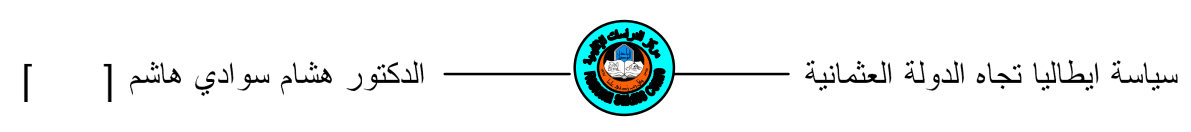

سياسه ايطاليا تجاه الدوله العتماتيه 1919 - |919

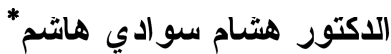

مستخلص البحث

صاغت المعاهدات السرية التي عقدها الحلفاء أبان الحرب العاب العالمية الأولى العي

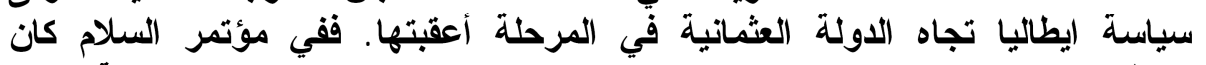

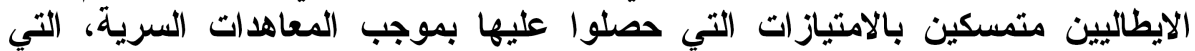

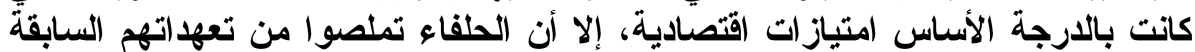

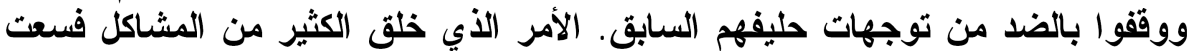

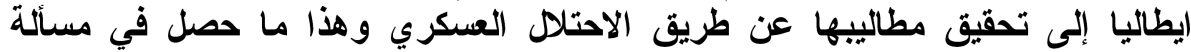

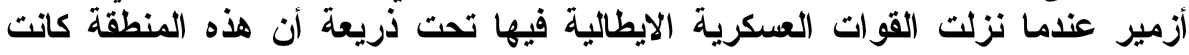

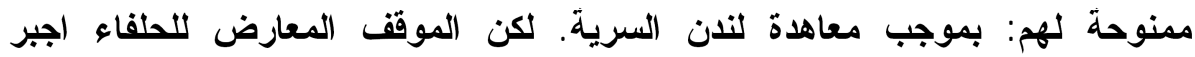

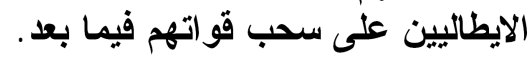

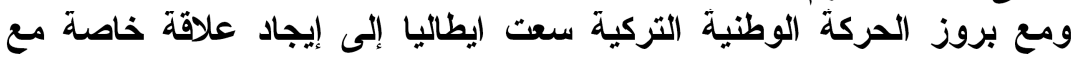

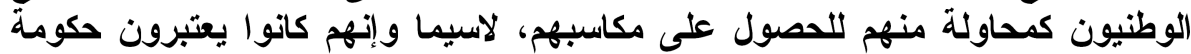

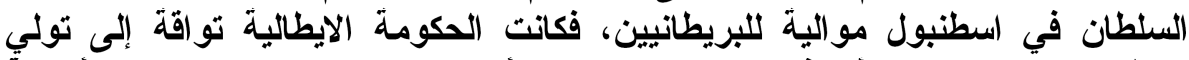

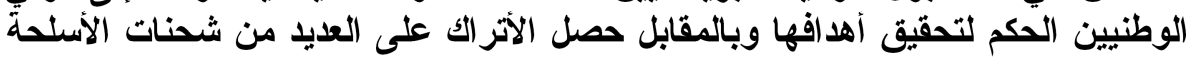

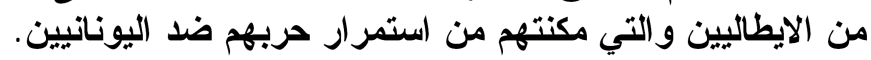

ملخل

ترتب على هزيمه الدوله العتماتيه وي الحرب العالميه الاولى وتوفيعها معاهدة مودروس Mudres في ·r تشرين الاول 1911 خسارتها لمعظم ممتكاتها. وقد انتهى الحكم العتماني في الحجاز بعد تورة الثريف حسين بن علي في عام 1917،كما

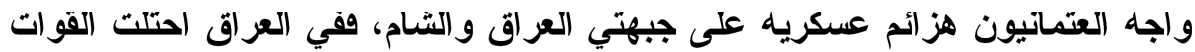

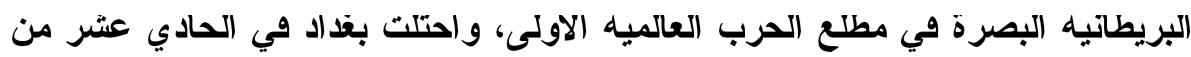
ادار 19IV، تم وصلت -اي القوات البريطاتيه - على مقربه من الموصل في تترين

* مدرس/ فسم التاريخ/ كليه التربيه، جامعه الموصل. 
الاول1911) 191) وفامت وي دمشق حكومه عربيه برئاسه ويصل بن الحسين بمساعدة القوات البريطانيه التي اكملت السيطرة على سوريا وفلسطين - وشروي الاردن للقترة من السابع والعشرين من تشرين الاول 19IV، وحتى السادس والعشرين من الشهر الشهي

(r). تقسه عام 1911

وعلى اتر تلك التطورات اضطرت الحكومه العتمانيه الى تقايم استقالتها في التالت عشر من تثرين الاول 1911، وهرب تالوت الحكم العتماني (انور، طلعت، جمل) الى خارج البلاد وشكلت بعدها حكومه جديدة برئاسه عزت باشا والتي ووعت لهت على بنود معاهدة مودروس.(r) تضمنت المعاهلاة خمس وعشرين مادة، نصت المادة الاولى فيها على حريه الملاحه وي مضيقي البسفور والدردنيل واحتلال استحكاماتها من وبل الحلقاء - ونصت المادة الرابعه على تسريح الجيش العتماني ويما عدا ووات صغيرة لحمايه الحدود و استسلام جميع الحاميات العتمانيه وي الحجاز وسوريا والعراق وعسير واليمن، وي حين نصت المادة السابعه التي كاتت اشد نصوص المعاهدة وطاة على الدوله العتمانيه، تخويل دول الحلقاء حق احتلال اي نقطه استراتيجيه يرون ان من مصلحتهم احتلالها. واكلت المادة الرابعه والعشرون على حق الحلقاء اخضاع اي ولايه من الولايات الارمنيه الست وهي: ولايه وان وارضروم وطرابزون وسيواس ويتليس وديار بكر،

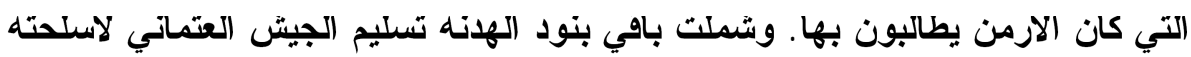
ومعداته. ومساهمه الضباط الاجانب وي الاشراف وادارة شؤون سكك الحديد التمانيه

وغير ها.(ع) ومعاه

واستنادا الى تلك البنود اولا وتطبيقا لما تم توفيعه من اتقايات سريه تانيا،(0)

بلات ووات الحلقاء تمتل المواقع المخصصه لها، ففي التالت عشر من تشرين التاني 1911 دخلت سفن الحلقاءمضيقي البسفور والدردنيل وبعدها الى القرن الدهبي، واتزلت وولتها وي اسطنبول وتحصينات المضايق، واحتلت القوات البريطانيه/الموصل والاسكندرونه تحت دريعه تامين خطوط تموين وواتها، كما احتلت عيتتاب ومرعش واوروه واسكي شهر واقيون وره حصار وكوتاهيه فارضين سيطرتهم على سكه حديد بغداد ومواتئ البحر الاسود.

ونزلت ووات بريطانيه اخرى في سامسون وطرابزون وارسلت بعض وه اتها الى انقرة ومرزيقون.(7) في حين احتلت القوات الايطاليه بعض المناطق في الاناضول 


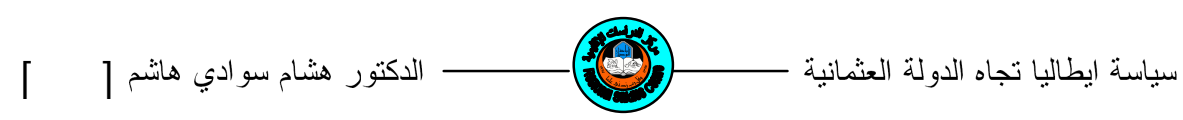

الغربيه والثريه ومنطقه ايلين والمنطقه الممتدة بمحاداة الجاتب الثروي من اسطنبول

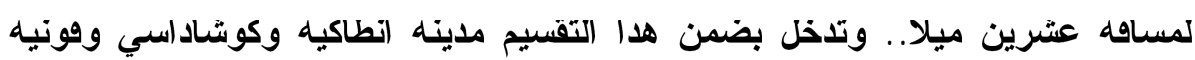
و اسبارطه، في الووت نفسه احتلت ووات فرنسيه بعض المواقع في اسطنبول وسيطرت

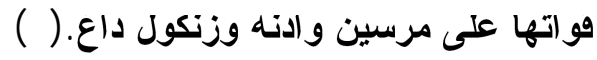
ايطاليا و ل(المساله التركيه) في مؤتمر الصلح: في صبيحه يوم التامن عشرمن كانون التاني 1919 اهتتح مؤتمر الصلح في باريس الاي كان مصير العالم يتوف الى حد كبير على نتائجه. وكان الناس يتلقفون

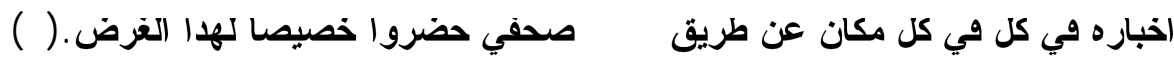

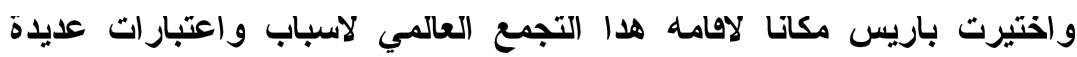
منها. اصرار الرئيس الامريكي ويلسون(9) ان تكون باريس محطه وليس جنيف لانها

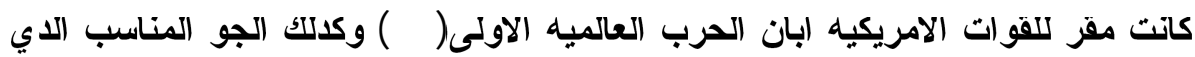

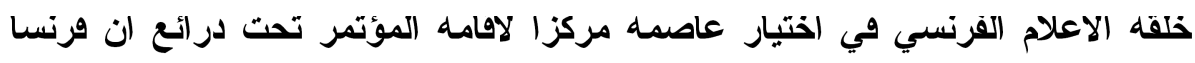
هي الدوله الاكتر تضررامادياوبشرياخلال الحرب من بين جميع دول الحلقاء ومؤكدين

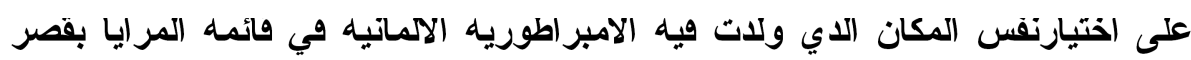
هرساي.

ادرج مصير الدوله العتمانيه او كما اسمتها ادبيات المؤتمر بـ (المساكه

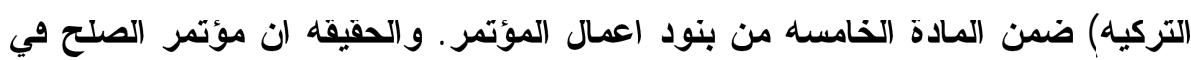
باريس لم يواجه مساله اكتر اهيه من المساله التركيه التي هي في جوهرها ود اتارت مساله دات اهيه وتاتير عالميين، وكان المؤتمر محاوله جليدة من جاتب الساسه لايجاد حل للمساله الشرويه(1Y) المزمنهوالتي اتبتت اتها ليست عقبه تقف في وجه السلام العالمي وحسب بل اتها ايضا الفتيل الدي اشعل نزاعات خطيرة ومنافسات حادة بين الدول الكبرى في اوربا.(Ir)

وبعد ان جرت المراسيم الاقتتاحيه للمؤتمر ورضت إلمساله التركيه) فسها بل تقاصيلها على المجتمعين. وكاتت هله المساله بالفعل موضوع مدكرات ومناهشات غير 
رسميه، ومند السادس من كانون الاول 1911 كتب الجنرال جان كرستيان ستس|عI)

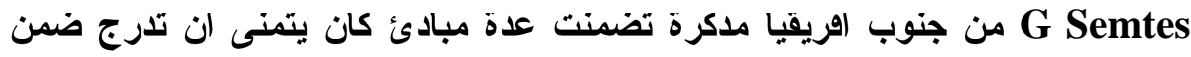

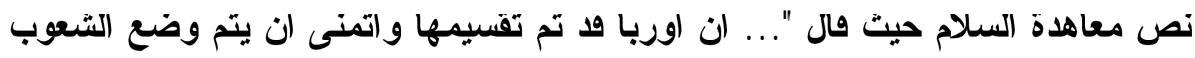
والاهاليم التي كانت سابقا تعود للاول العتماتيه... تحت وصايه عصبه الامم."(10) ولم يكن سمتس على حد راي احد الباحتين راغبا في وضع اي من تلك الاهاليم الى اي لدوله من الدول المنتصرة اد راى ان قاعدة الحكم الداتي) او هبول المحكومين بثكل

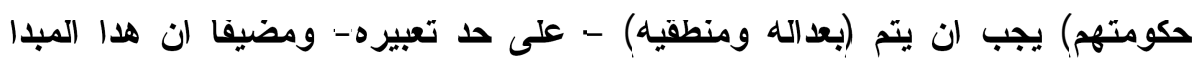
يمكن تطبيقه في العراق وسوريا(1) ادى امتلاك دول الحلقاء لمناطق نقود وي مختلف اتحاء الدوله العتمانيه الى تصادم وتقاطع مصالحها وبالتالي نجد تمه اختلاف كبير وي وجهه نظر كل دوله حول المصير التهائي للاوله العتمانيه. وبالتحديا وان ايطاليا وصرنسا وبريطانيا والولايات

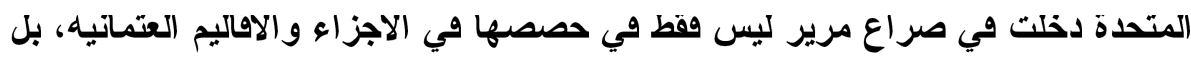
حول السيطرة على اسطنبول والمضايق ايضا. هكدا كان حال المساله التركيه عندما تم عرضها امام مندوبي الدول الكبرى في

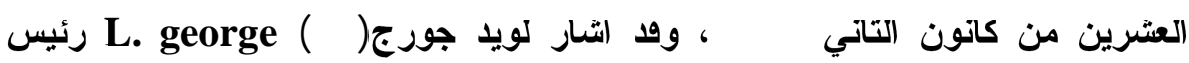
الوزراء البريطاني الى ان مبدا الوصايه في جميع ممتلكات الدوله العتماتيه د تد تم القبول به الان غير انه اصر على تحديد تلات درجات من الوصايه هي:

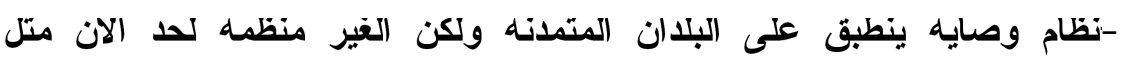

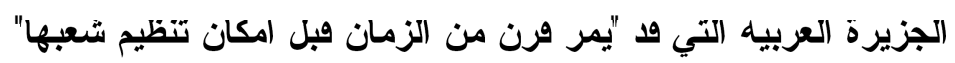
r -نظام وصايه ينطبق على البلان الاستو ائيه.

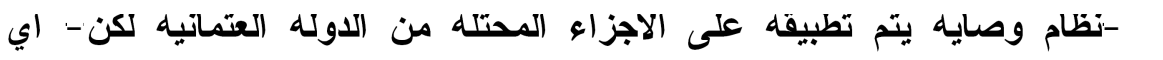

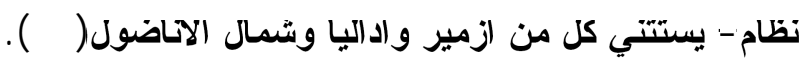
ويبدو ان هلا الاستتناء من الوزير البريطاني جاء بسبب اعتقاده ان هله المناطق التي حلدوها ستكون موضوع تنازع بين الدول للسيطرة عليها، وهدا ماحلث وعلا وسنلاحظ دلك لاحقا في سياق معالجتنا لمشكله ازمير. ابلى الوضا الايطالي اعتراضه على اوكار لويد جورج وهال رئيس وزراءه اورلاندو/(19) Orlando (انه لايرى ان من الضروري البلء بنقاش حول التقسيم

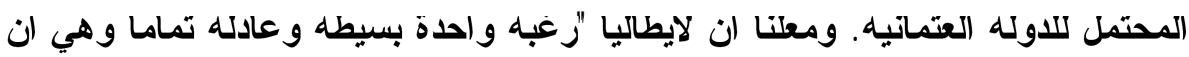




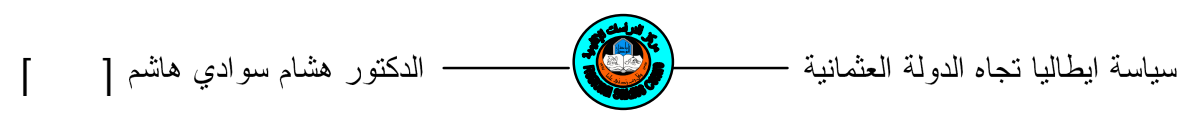

التوزيع المناسب بين الحلفاء يجب ان يتم في ضوء احتلال تلك الاصاليم"، وكل ماطالب به هو ان تحصل بلاده على "تصيبها من الوصايه او من الاهاليم لتي سيتم احتلالها عسكريا'(·r) والحقيقه كان هلا هو الموفف الايطالي سواء تم تطبيق نظام وصايه

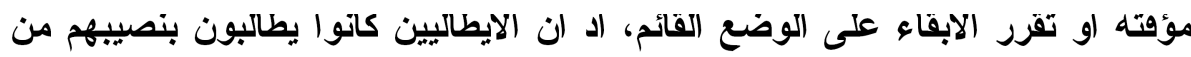

(الغنائم التركيه.( ) (1)

ويبدو ان الموهف الايطالي جاء بسبب الاملاءات القوميه التي شكلتها

الامتيازات الممنوحه لايطاليا وفق المعاهدات السريه ويضيف لنا المؤرخ الآكليزي هيشر هلا الامر بقوله "..اما ايطاليا ووقت وي مؤتمر الصلح موهفا املته عليها مصالحها القوميه البحته، ولم تبلبل اوكار خيريه واسعه المجال ادهان الساسه الايطاليين الوافعين ولم تجش في نفوسهم نزعات انسانيه جميله، ولم تعب روما الا وليلا بعصبه الامم التي كان انشاها معزيا لقوب الكتيرين من ابناء الثّوب الأكلوسكسونيه عن خطوب الحرب وويلاتها. واخد انصار البابويه يسائلون انفسهم الاتعتدي هلده العصبه عن حقوق القاتيكان وامتيازات القديمه (بقرض وساطته على الامم المسيحيه (المتناز عه'(ب)

وي التلاتين من كانون التاني 1919 جرت مناهشات جليدة بين الاربعه الكبار(سM) اد انه ود تقرر مسبقا ان تنقصل اهاليم ارمينيا وفلسطين والجزيرة العربيه و العراق عن الدوله العتمانيه، على ان يتم لاحقا تقرير مصير وضعها النهائي. وصد بادر لويد جورج بالتحرك لشمول منطقه اخرى ضمن المناطق المقرر اهتطاعها من الاتر(كئل "... ولقد اشار الى كردستان التي كاتت و اقعه بين العراق وارمينا'، اد كان مهتما بقيام منطقه عازله بين الموصل وتركيا.(عr) ولكنه وي الووت نقسه كان يرى باته يتوجب لئه

ان تتولى دوله ما الوصايا هناك لغرض حمايه شعوب تلك المنطقه.(ro)

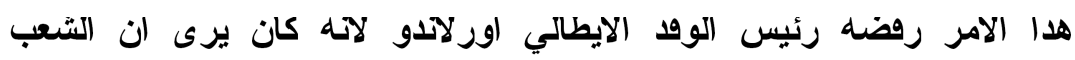
الايطالي الايمكن ان يرهض شيئا اكتر من القبول بمسؤوليه عسكريه في اسيا، ولكنه

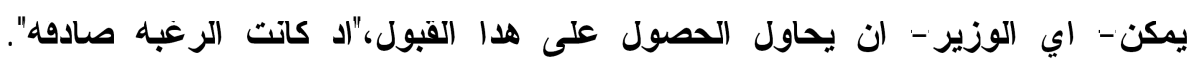
و اقترح بان تقوم السلطات العكريه للحلفاء بارسه مساله الاحتلال العسكري، وراى 
ان مساله سحب القوات سيكون صعبا طالما ا الحكومـه الروسيه (البلشفيه)(דا) الجديدة

كاتت تتير خلف الحلفاء وعبر اورلآدو بوصفه لها"'كاتت عنصرا غير مضمون"'(rV) وصررت ايطاليا الطلب من مندوبيها العسكريين روع توصياتهم حول التوزيع الاوتصادي الانسب لمسؤوليه ارسال ووات لحفظ النظام في تركيا والقوهاز مي انتظار رزارات مؤتمر باريس بخصوص الحكومه التركية.(YK) ونلاحظ ان الايطاليين كانو يضعون مصاحهم الاقتصاديه في المرتبه الاولى في تعاملهم ميع المساله التركيه والتي هي بلدرها صاغت اتجاه سياسي سعه ايطاليا من ورائه الحصول على المناطق الغتيه بالتروات الطبيعيه وي تركيا لاسيما مناجم الفحم. وضد اختتم اجتماع الحلفاء وي دلك اليوم بالتوصل الى ورار اكدوا ويه اتهم

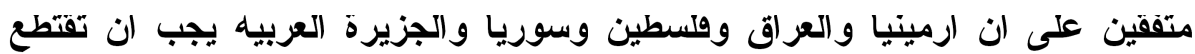
نهائيا من الدوله العتمانيه على ان يتم دلك "من دون التاتير علىتسويه الوضع في لئي

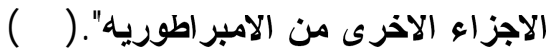
السياسه الايطاليه تجاه مساله ازمير: سمح الحلفاء لكل الاطراف بطرح مطاليبهم وكان اولهم الوضد اليوناني برئاسه هينزليوسلrVenzilos(r) رئيس الوزراء، الدي حارب طويلا من اجل توحيا جميع

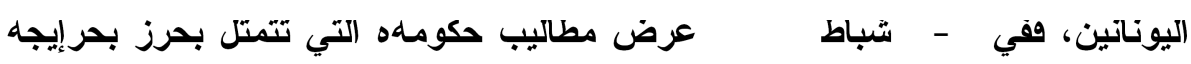

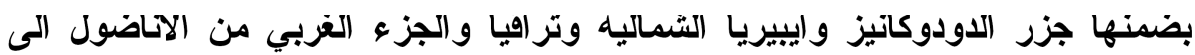

غرب الخط المرسوم بين كاستنرويزو وبحر مرمرة باستتاء منطقه المضايق.(II)

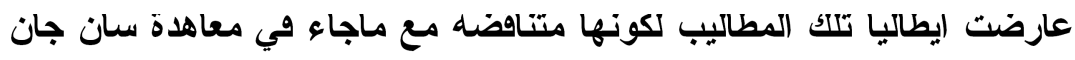

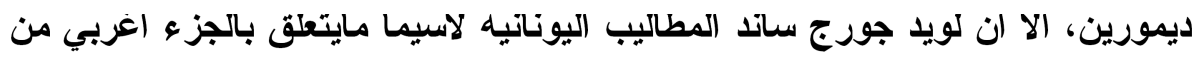
الاناضول رغبه منه بالحصول على دوله صديقه تسيطر على بحر ايجه لمواجهه اي

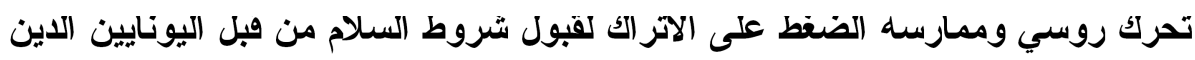

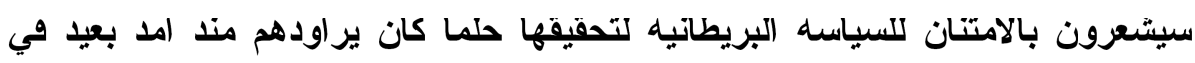

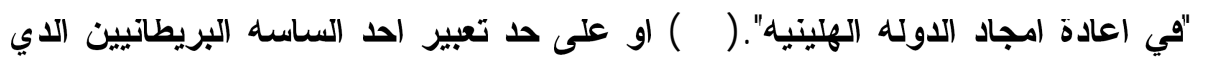

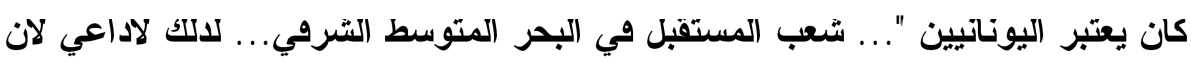

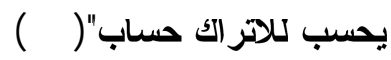




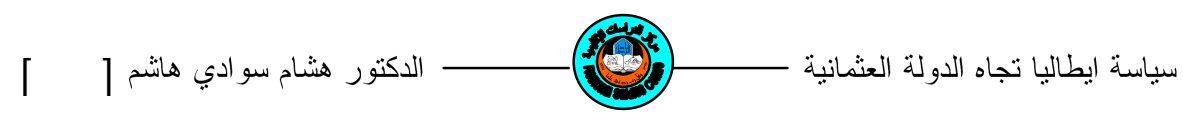

وضضلا عن دلك هان اليونان يمكن السيطرة عليها على العكس من ايطاليالتي

تعد من الدول الكبرى لاسيما وان ماستحصل عليه في الآناضول هو من حقها لقاء ماعدمته وي الحرب. لالك عارضت بريطاتيا المطالب الايطاليه، معلله الامر، بان معاهدة

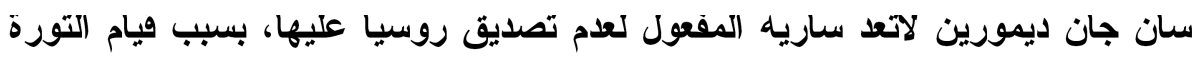
البلثفيه، ومؤكدين ان حصه ايطاليا تقتصر على انطاليا بحسب معاهدة لندن لندين السريه.(عr) ودعا لويل جورج ان تتم دراسه المطالب اليونانيه من وبل لجنه خبراء

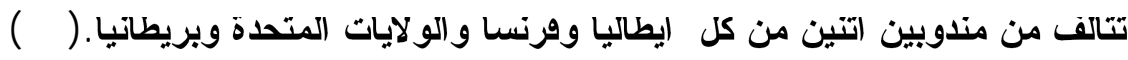
استغرق الامر حتى السادس من ادار لكي تكمل اللجنه المكلفه بار اسه المطاليب اليونانيه، تقريرها الاي روعته الى مجلس الاربعه الكبار. وصد واهقت كل من بريطاتيا وهرنسا والولايات المتحدة على المطالب اليوناتيه في غرب اليبريا الثماليه ولكنه

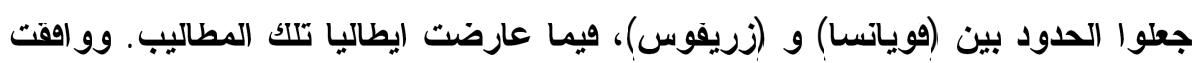
الدول الاربعه على مطلب اليونانيين في شرق وغرب الارخبيل مع بعض التعديلات،و

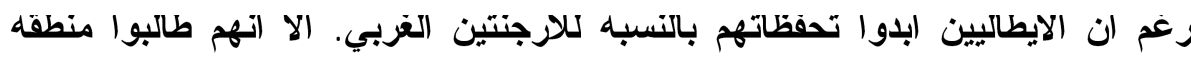

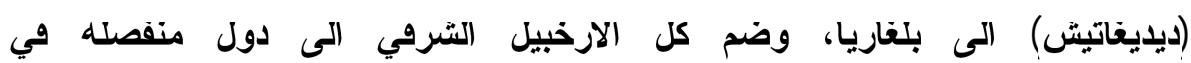

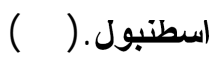

امسا فيما يخص الجاتب الغربي من الاناضول هان ايطاليا لم تتقلد بايه توصيات لان تسويه هده المساله لايمكن ان تكون بمعزل عن الحل الشامل لكل الاناضول، وضلا

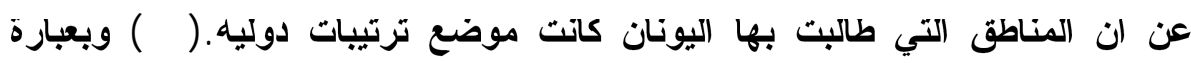

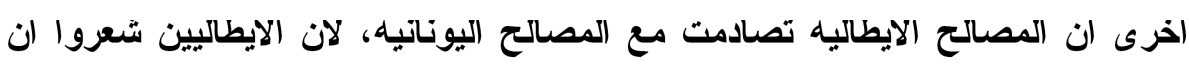

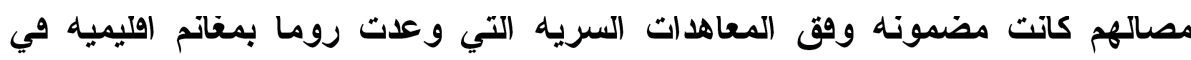

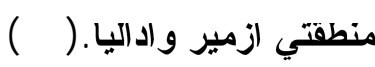

سعت ايطاليا وخلال الاسبوعين الاولين من نيسانو1919 الى نشر وواتها وي شمال بحر الادرياتيك واعلتتها مقاطعه ايطاليه، وبدات تطالب بما وردوي معاهدة لندن النين السريه. وصام رئيس الوض الايطالي اورلآدو في التاسع عشر من نيسان مدكرة بشّان

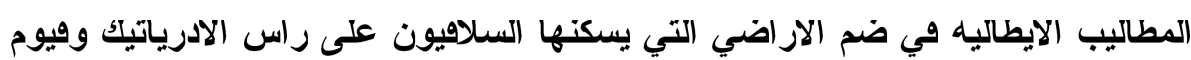


وبعض الجزر البعيدة عن ساحل دلاماشيا والساحل نفسه. وعلل اورلآدو سبب دلك حاجه ايطاليا لحمايه نفسها من تكتلات ود تقيمها النمسا مستقبلا. ومعلنا ان بلادة وتتفيلا لمعاهدة لندن ستكمل تمركزها في مقاطعه اداليا بعد منتصف نهار دلك اليوم.(rq) وتلدارك هدا الموفف ولاخراج الوضع من عنق الزجاجه اقترح لويد جورج انه يمكن للايطاليين ان يتساهلوا في مساله بحر الادرياتيك، الد ما اعطوا وصايه في الاناضول وراى كليمنصو Klemenso( - ع) رئيس وزراعرنساورئيس الوضا الفرنسي في المؤتمر ان تلك الوصايه يمكن ان تشمل جزء من الآاضول محادي لمنطقه وصايه (ع اليونان ومنطقه اسطنبول. (ع) تحدث الرئيس الامريكي ويلسون مع رئيس الوزراء الايطالي وناهته في بعض الفقرات التي وردت وي مدكرة الاخيرة، موضحا له انه لايمكن لاحد ان يقدم المساعدة لايطاليا لان سياستها لاتتسجم مع توجهات المؤتمر ولاتحظى بقبول الشعوب. لكن

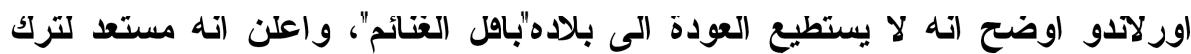
مساله ويوم ليناهشها الاربعه الكبار، مشترطا وي الووت نقسه ان تكون معاهدة لندن السريd1910 اساسا لمنافثه حقوق ايطاليا، لكن الرئيس الامريكي بادره بالقول انه

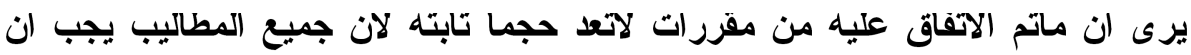

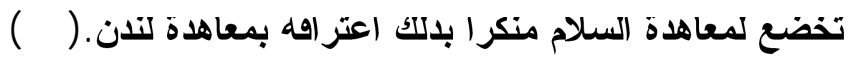
حدر اورلآدو في اجتماع اليوم التالي من فيام تورة شعبيه وي عموم ايطاليا

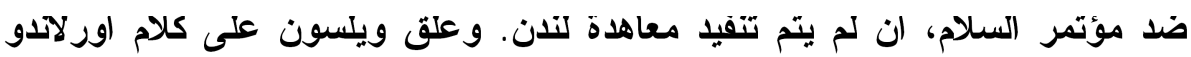

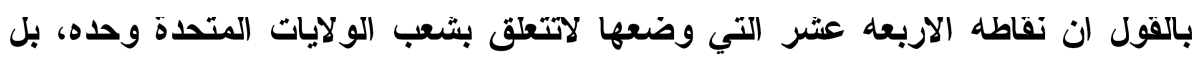
بجميع شعوب العالم وهي لتسويه مشاكل الاهاليم ومن بينها مشكله ايطاليا والبلقان، وان المواهقه على المطالب الايطاليه بالثكل الدي يعرضه رئيس وزرائها سيخلق مشاكل

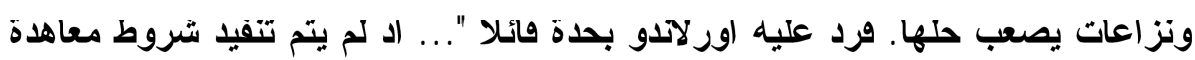
لندن هان ايطاليا ستقف في طريق السلام ولن ترضخ لضغط او رغبات دول المعاهدة

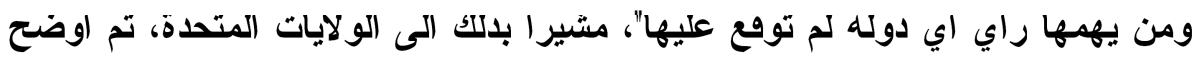
ان مبلادة مخاوف جمه من النمسا التي لم يتم تحليد وواتها، لا فان على ايطاليا حمايه

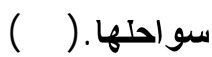
اقترح لوميا جورج ي اجتماع اليوم التالي -وبغياب اورلآدو عمنح الايطاليين سواحل دالماتشيا وميناءها دون ويوم، داكرا انه علم من اليوغسلاف انهم لا يهتمون 


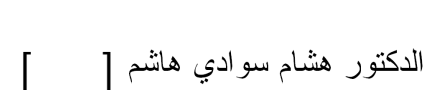
سياسة ايطاليا تجاه الدولة العثمانية - س

بهاه الجزر.. لكن ويلسون اعترض على دلك واوضح ان القوميين الصرب لن يقبلوا

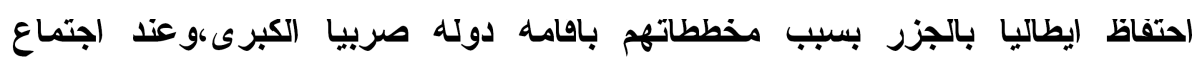

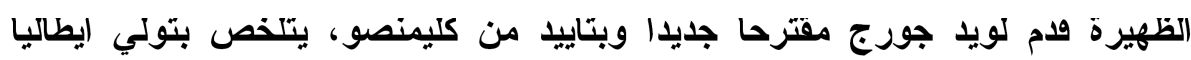

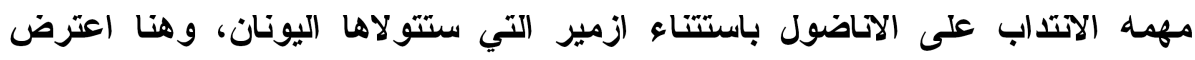

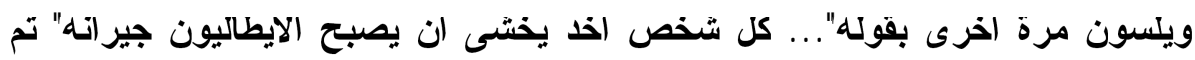
اضاف "لقد التام شمل المؤتمر على اقتراض تاميين السلام العالمي وليس الدخول في

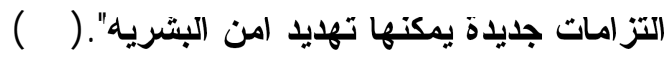
دوع الموفف الامريكي المعارض بلويد جورج لتقليم مقترح جديد ينص على التصن منح الايطاليين بعض التاتير في المنطقه بلالا من الاتلاب، لكن بعض الدبلوماسيين شككوا في نجاح الايطاليين في هلا الامر بسبب اهتقارهم الى متل هده التجارب، فضلا

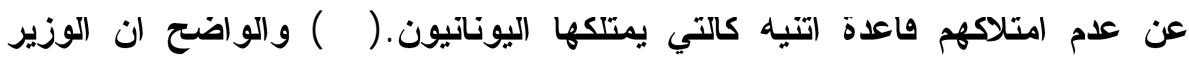
البريطاني اراد اعطاء الايطاليين بعض الامتيازات الاوتصاديه لاسيما التجاريه، وليس ليس لئه منحهم سلطه سياسيه وي تلك المناطق وبالتالي عدم ظهور اي دوله تمتلك مناطق نفود و التي من شانها منافسه بريطانيا صاحبه النقود التاتير الاكبر في تركيا. هلد اورلآدو باتسحاب بلاده من المؤتمر، لا اضطرت الدول التلات الى

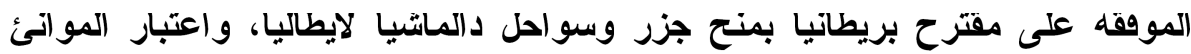

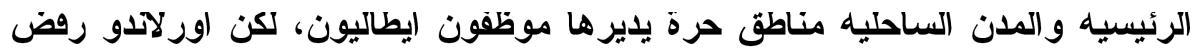
العرض واصر على حصول بلاده على موانئ المنطقه برمتها، رض التلاته الكبار

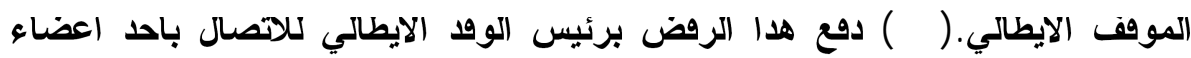

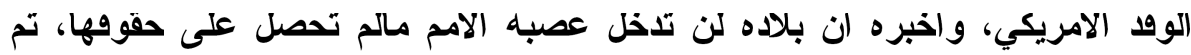

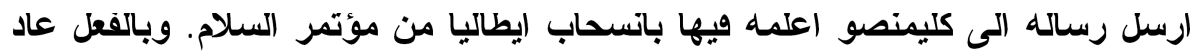

(EV). اورلآدو واعضاء الو والى روما وي السادس و العشرين من نيسان 1919 اجتمع التلاته الكبار في التاني من ايار لمتابعه المساله التركيه، واعلن لويد جورج حتلال الايطاليين لميناء مرمريس كمطه للتزود بالوفود واتزلت هرفه ايطاليه في وونيه كما تم اتزال بعض القوات في اداليا.(ع) لالك اهترح ويلسون ارسال الدول 
التلاث سفتها الى تلك المنطقه، ولقي مقترحه مواققه الجميع، وارسلت الولايات المتحدة سفنها يواس. اس. (يرزونا U.S.S. Arezona الى ازير واخرى الى فيوم، وفعلت بريطانيا وورنسا الشيئ نقسه لمراوبه الايطاليين الدين وسعوا مناطق احتلالمه لتشمل جنوب الاناضول كله، وارسلوا لاستقدام ووات ايطاليه جديدة، ووي غضون دلك تم تنافل

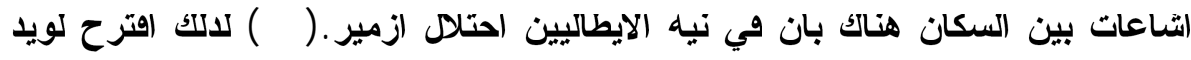

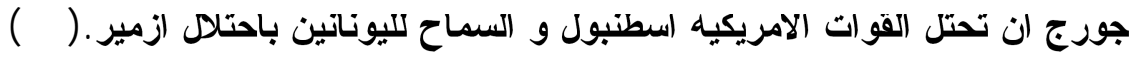
في السادس من ايار اعلن ويلسون ان بلاده لن ترسل فوات الى تركيا، لاتها

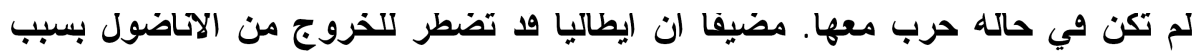
اعتمادها على الولايات المتحدة في دعمها المادي، وان ويام وصايه ايطاليه في الاناضول سوف'تتسبب وي شقاق عميق". وفي الوهت نقسه راى ويلسون ان الفائدة

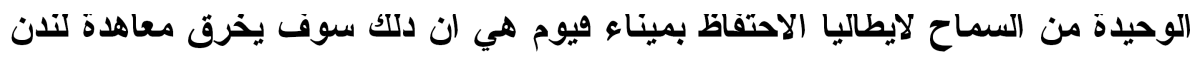

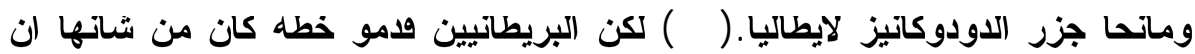
تحل المشكله - حسب وجهه نظرهم - ونصت على منح الولايات المتحدة وصايه على

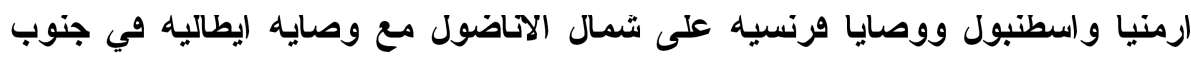
الألضول تشمل ميناءي ماكري ومرسين وحصه من مناجم الفحم في هرويليه. لكن الايطاليين طالبو بـ سكا لانوها، مما جعل القرنسيين والامريكان يرضضون المقترح

$$
\text { (البريطاني.) (Or) }
$$

عاد لويد جورج واقترح في اليوم التالي السماح لليونان بنتر وواتها في ازمير

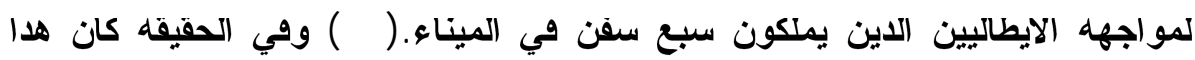
المقترح مناورة سياسيهبارعه وهي في ظاهرها استجابه لمطاليب اليوناتيين الدين سيسعون جاهدين لنشر وواتهم هناك، وصي جوهرها هي (بعاد الايطاليين عن ازمير باظهار الدعم لليوناتيين، وبالتالي ستتحاشى القوات الايطاليه الاصطدام بالقوات اليونانيه

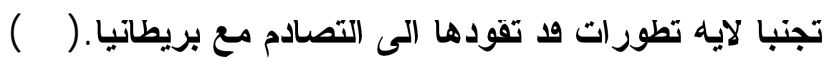
عاد الو والايطالي الى مؤتمر السلام بعد سماعه بقرار التلاته الكبار واقترح لويد جورج ورض الاتتداب على تركيا وتقسيمه على الدول بمشاركه ايطاليا واليونان. وفي الرابع والعشرين من نيسان فسم الاتتاب على الاناضول بين ايطاليا وورنسا واليونان، ولكن ووبل تحديا اماكن الدول التلاته استبلت ايطاليا وواتها البحريه بقوات التين 
] الدكور هشام سو ادي هاشم [ [ I I ] سياسة ايطاليا تجاه الدولة العثمانية

بريهاستقرت في الساحل الجنوبي للاناضول وفامت بتوسيع حدود الاقليم الدي سبق

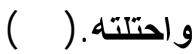

اتزلت اليونان فو اتها في ازمير ليله عات 10/1 ايار بحمايه بريطانيه وامريكيه،

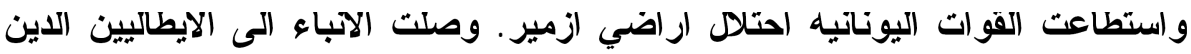

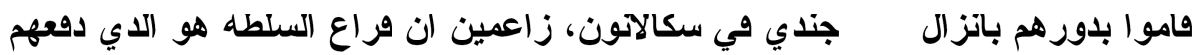

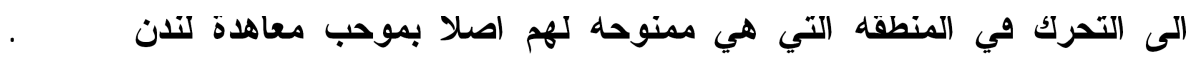

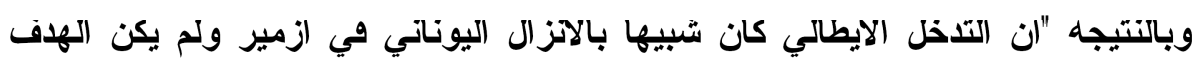

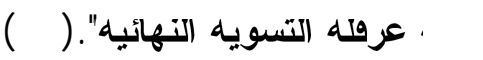

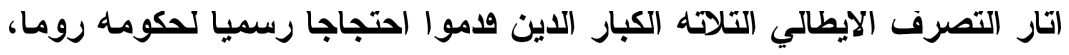

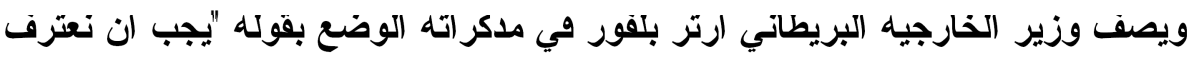

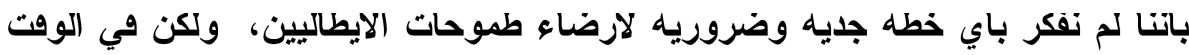

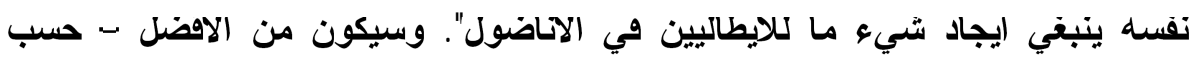

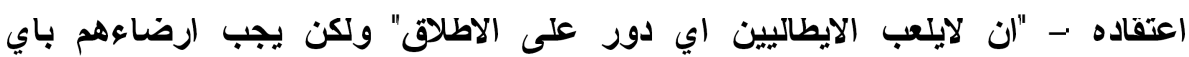

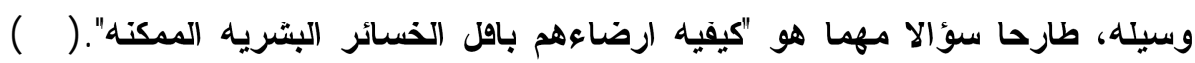

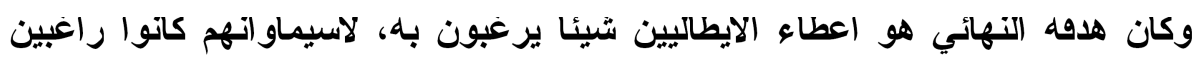

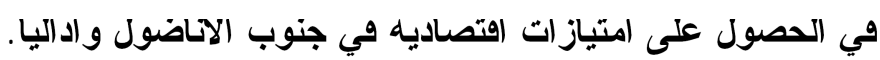

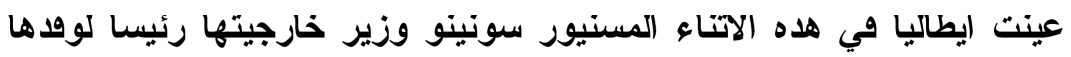

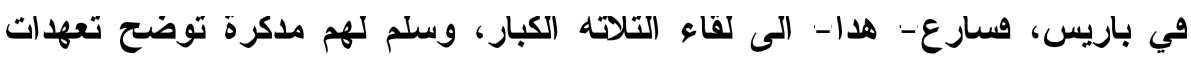
الحلفاء في معاهاتي لندن وسان جان ديمورين اللتين تخولان ايطاليا التملك وي

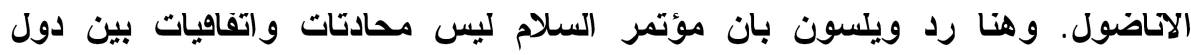

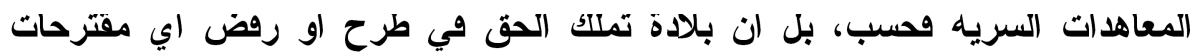

$$
\text { بغض النظر عن الاتفاهيات السريه.(01) }
$$

حاولت بريطانيا مساومه نظيرتها عندما اعلتت انها على استعاد للتظلي

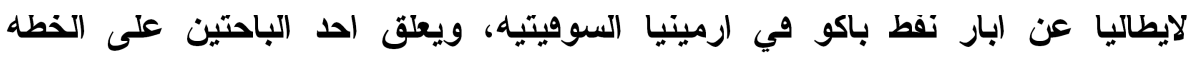

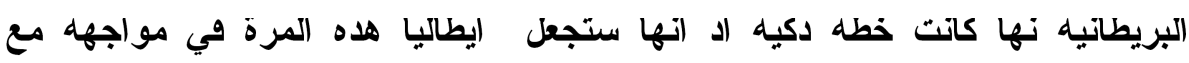


القوميين الارمن الدين يعدون ادربيجان ضمن ولايات ارمينا الثرويه ويزعمون انه

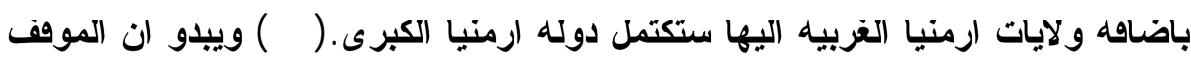
البريطاني المعادي للطموحات الايطاليه يعود وي القسم الاكبر منه للمنافشه الاستعماريه. لالك لقي المقترح البريطاني معارضه الدول الاخرى، وشعر سونينو ان حلقاء بلادة

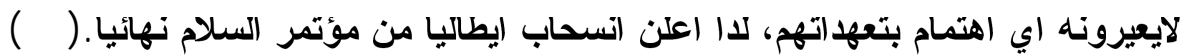
وكاتت (يطاليا ود حاولت تدارك لموف بعلد صلح مع اليونانيين لتجاوز خلافاتهما والوصول الى اتفاهيه تضمن مصالح كلا البلاين مما يحول دون تصادهما، ونصت المعاهدة على دعم موفف بعضها البعض امام المؤتمر، وواققت ايطاليا على التوغل اليوناني في كل من الارخبيل الثروي والغربي وكلالك في اييروس الثماليه، مقابل امتيازات افتصاديه للايطاليين. وتعهرت اليونان بدعم سيادة ايطاليا على منطقه قالوفا مي منحهم امتيازات اهتصاديه وي ازمير وان يحتفظ الايطاليين بجزيرة رودس. واشترطت المعاهدة في حال عدم حصول الدولتين على كل مطاليبهما فسوف تستسفان

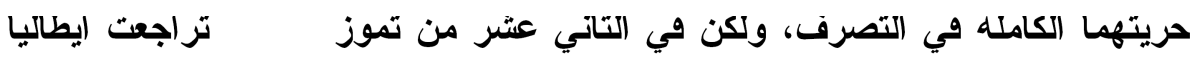
عن الاتفايه مما ادى الى فشلها.(11) والحقيقه كان اكتر ما اتار غضب الايطاليين فشلهم في الحصول على ميناء

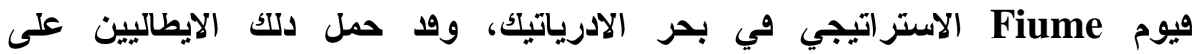
استخدامهم القوة لضم الميناء الى (يطاليا، الد الدم بضع مئات من الجنود الايطاليين على الئ احتلال الميناء تحت ويادة غابريلي داتزيو Gabriele D'anaanzio وهو شاعر رومانسي مشهور غدا بطلا وميا بنظر الايطاليين. وصد استمر احتلال ويوم خمسه عشر شهرا تقرر بعدها جعلها مدينه حرة ومفتوحه بوجه تجارة البلاين على اتر معاهدة

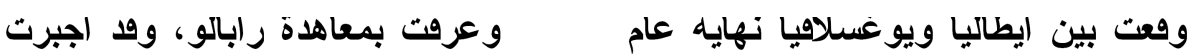
الحكومه الايطاليه ووات واتزيو على الآسحاب من المدينه، وصد اتار تصروها هدا انتقادات شديدة من جانب الوطنيين الايطاليين الدين اعتبروه خضوعا مهينا من النئ

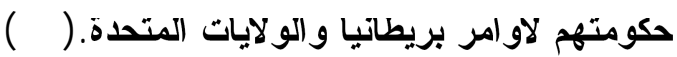
اصيب الساسه الايطاليين بخيبه امل بسبب الوفف المعادي لحلفائهم في لرياي المعاهدات السريه، وبريطانيا وهرنسا اللتان ووقتا الى جاتب الولايات المتحدة وضد التوجهات الايطاليه التي املتها الامتيازات الممنوحه لها بموجب المعاهدات السريه. منطلين من مبدا ان الايطاليين لم يبلولوا جميع الجهود التي انتظروها منهم، لالك همن 


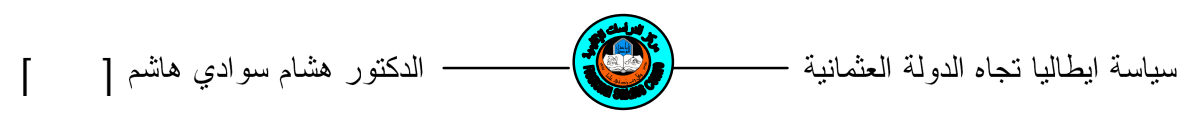

غير المعقول ان يحصلوا في معاهدة السلام على كل مايرجون وياملون، مما حدا ببعض الساسه الايطاليين التنديد بسياسه حكومتهم لاخفاهها في تحقيق مصالحهم التوسعيه

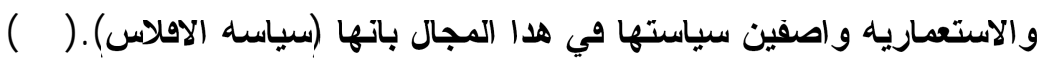

سياسه ايطاليا تجاه الحركه الوطنيه التركيه: في الووت الدي كان ويه الحلقاء مجتمعين لتقاسم اسلاب الدوله العتمانيه، كان الاتر الك ورغم الاتهاك الدي اصابهم خلال الحروب الكتيرة التي خاضتها الدوله العتماتيه،

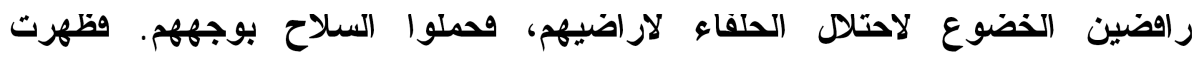
الجماعات المسلحه في مناطق مختلفه من تركيا وخلال وترة وصيرة اتتشرت في طول البلاد وعرضها. وبلات مند دلك الحين تتنكل ملامح حركه وطنيه شعبيه منظمه. ورغم اتها كاتت تتسم بالعقويه وبل الاحتلال اليوناني لازمير، حيث كانت الجماعات المسلحه

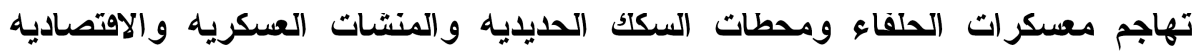
الخاضعه لسيطرة الحلقاء.(1)

بدات التقارير الصحقيه ومند التامن عشر من ايار 1919 - اي بعد تلاته ايام

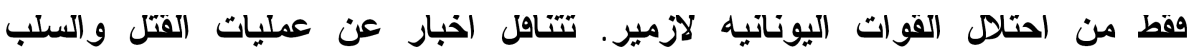

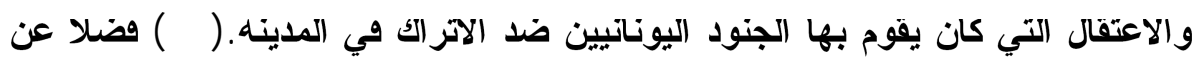
تصرهات الايطاليين - لاسيما البريطانيين والقرسيين المهينه للشعب التركي، ادت الى لى رد وعل ووي تمتل بالمظاهرات التي عمت مدن الآناضول - التي روعت شعار (ازمير تركيه) و اتهم (سيفعلون كل شيء من اجل الحفاط عليها) راقضين الحكم اليوناتي.(77) ولكن حتى دلك الوهت كاتت الحركه الوطنيه التركيه عاجزة عن تنظيم نقسها في جبهه واحدة لاهتقارها الى القيادة التي تستطيع تولي متل هلا الامر، لالك كان ظهور شخصيه مصطفى كمال.(7V) نقطه تحول في تاريخ الحركه الوطنيه التركيه المعاصرة. وفي التاسع من ايار 1919 ارسلت الحكومه العتمانيه مصطقى كمال الى لى الاناضول هائدا عام للجيش العتماني التالت المرابط في ارضروم وسيواس لحفظ الامن و النظام. وما ان وصل الى هاتين الولايتين، حتى اعلن انه لن يقبل بهزيمه تركيا، لالك 
صم مي عدد من انصاره على مقاومه ومعارضه اعمال الحلفاء غير المشروعه. و اخد

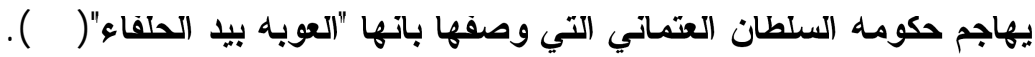
اتصل مصطفى كمال ببعض اصدهاءه القدامى الدين يتق به امتال عصمت

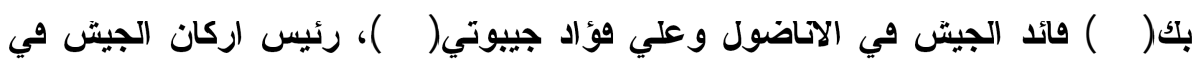

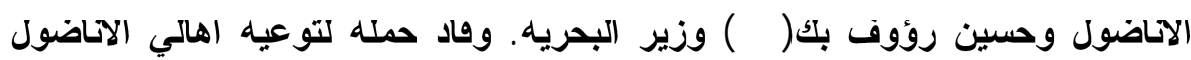
بما يعنيه احتلال الاجاتب للبلاد وطلب منهم القيام بحركه كفاح مسلح وتنظيم دعوات وتداءات بجلاء القوات المحتله من البلاد(VT). وعمل كدلك على الاتصال بجمعيات

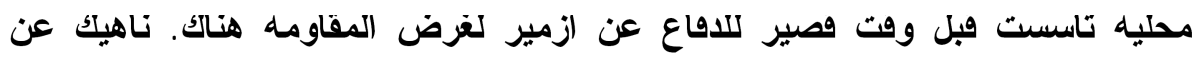

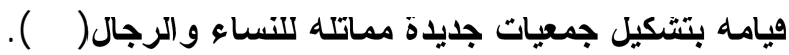
لقيت الدعوة التي بعت بها مصطفى كمال إلى نواب الولايات الثرويه لحضور

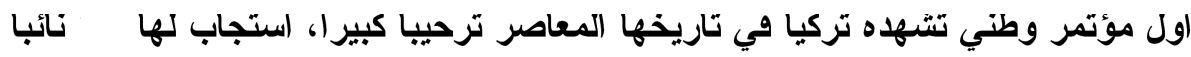
يمتلون ولايات ارضروم وبتليس وسيواس ووان ودياربكر وملاطيالع). وافتتح

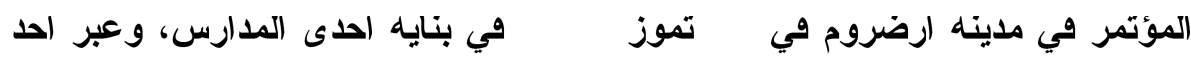
الباحتين عن اقتتاح المؤتمر انه كان بمتابه نقطه تحول في تاريخ تركيا المعاصرة والخطوة الاولى لانشاءها(V0). وخلال الجلسه الاتتتاحيه اختير مصطفى كمال رئيسا

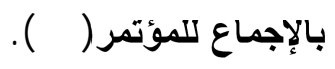

نجحت الحركه الوطنيه مع مرور الووت في تحقيق الانتصارات العسكريه، وإلى دهر

جاتب دلك نجح مصطفى كمال في تحقيق صلات دبلوماسيه ساهت إلى حد بعيد في تحقيق خطوة مهمه اتبت للحلقاء إن الحركه الوطنيه هي الممتل الحقيقي لمصالح الشعب التركي والحقيقه ان مصطفى تعامل بدكاء في دبلوماسيته ميع الحلقاء مستتمرا مساله الخلاهات السياسيه وبما بينها وضلا عن استفلامه الهوة بالواسعه التي كاتت تفصل الاوربيين عن حكومه البلاشفه وي روسيا. ومستفيدا من التناهضات بين كلا

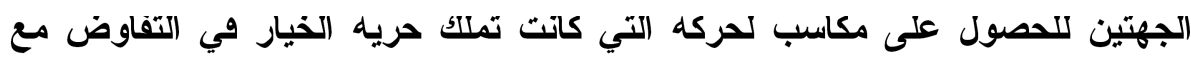
الحلفاء او مع روسيا، او مع كليهما وي نقس الووت. وكل مكسب تحققه مع احد

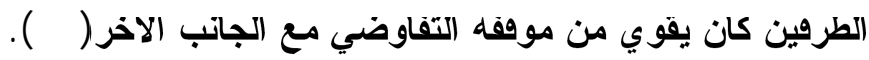

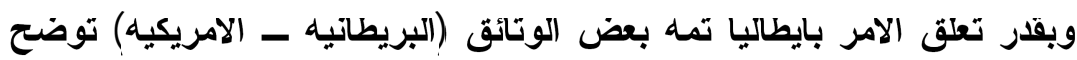

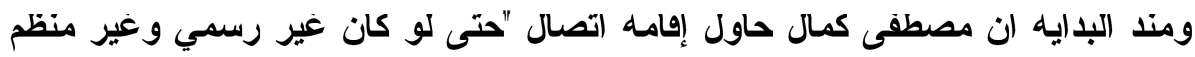

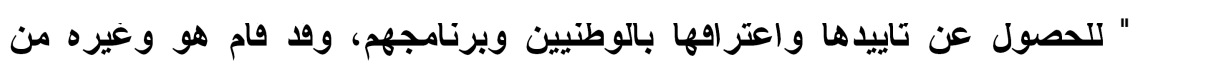




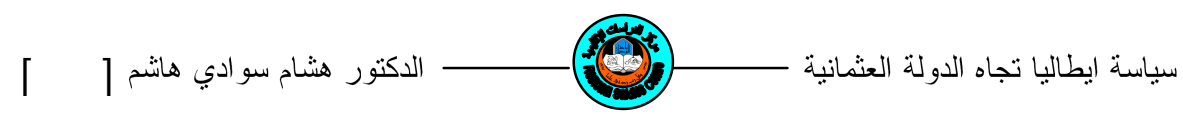

الوطنيين بمقابله العديا من ضباط المر اقبه التابعين للجيش الإيطالي، ضضلا عن مبعوتين

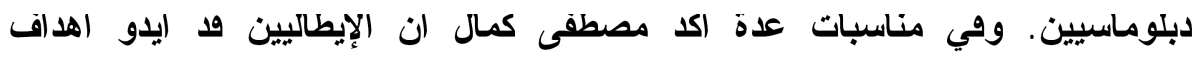

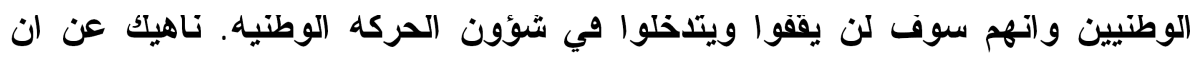
ممتليهم في سيواس كانوا يبعتون بتقارير إيجابيه إلى الحكومه الإيطاليه في روما عن لهن الوطنيين و (اتتصار اتهم/VM). وتاكيدا على ما سبق فاته إبان احتلال البريطانيين لاسطنبول في السادس عشر الهر

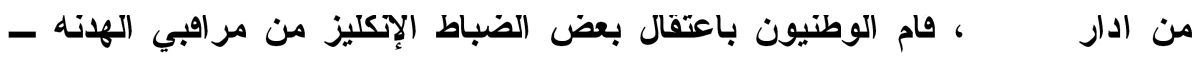

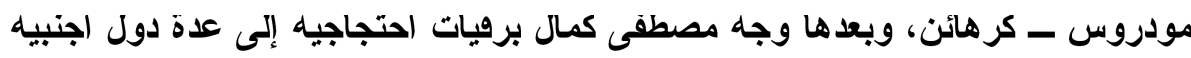

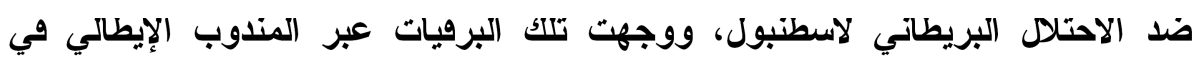
انطاليا، ادا كان الوطنيون يتلقون تاكيدات خاصه من الإيطاليين، لاسيما من رئيس

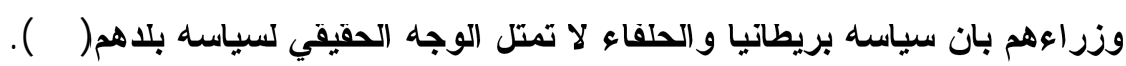
ومما ساهم وي اتجاه دعم الإيطاليين للحركه الوطنيه هو مووفهم المضاد من لهن

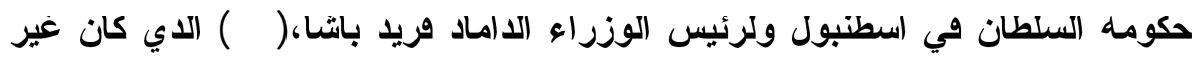
مرغوب به من وبل إيطاليا التي كاتت تعتبره وبحسب تعبير إحدى الوتائق البريطانيه

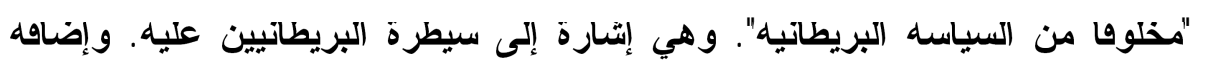

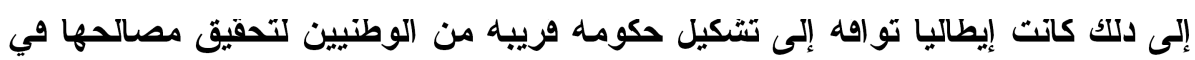

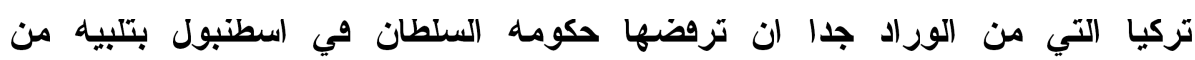

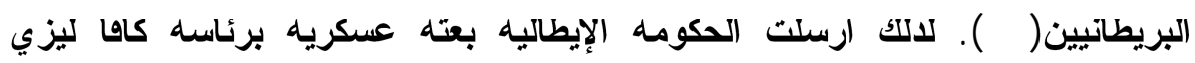

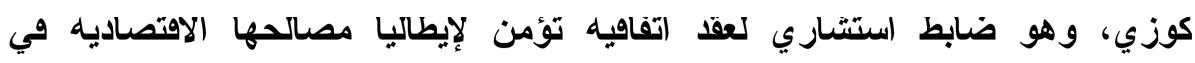

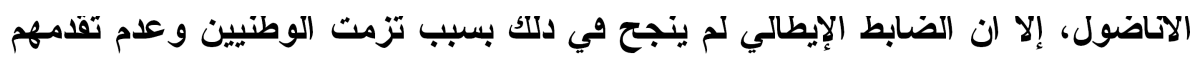

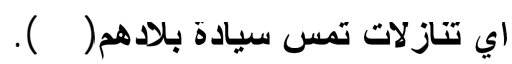

دعمت الحكومه البلثقيه في روسيا الحركه الوطنيه التركيه بالمال، الدي نجح

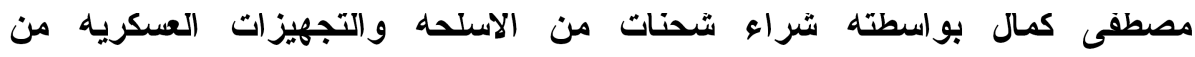
الإيطاليين(Ar). ويبدو ان المؤهف الإيطالي جاء بسبب غضبهه من احتلال اليونان

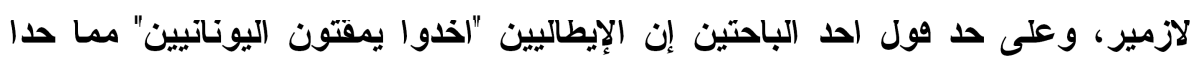


بمصطفى كمال من استغلال الموف فارسل بعض رسله إلى القادة الإيطاليين يعرض عليهم سلام مستقل عن حكومه السلطان وي اسطنبول، وفي اتتاء اللقاء طلب الوضد التركي من الإيطاليين سحب وواتهم من ادليا ومن جنوب غرب الآناضول مقابل منحهم امتيازات اقتصاديه في حقول الفحم في هرولييه التي كان الايطاليون يطحون في (السيطرة عليها.(1) اتار الموفف الإيطالي من الحركه الوطنيه مخاوف بريطانيا التي اشتار رئيس وزر ائها لويد جورج إلى ان"الوطنيين الاتراك سيتمكنون من اجل تحقيق انتصارهم على

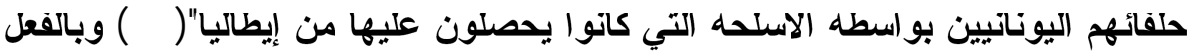
ها ما حصل وعند تويع إيطاليا على معاهلاة سيقر انسحبت القوات الإيطاليه من المناطق التي كاتت ود احتلها وي جنوب الاناضول. وفد تخلى الإيطاليين عن كميات كبيرة من الاسلحه للوطنيين عززت من مووفهم وجعتهم يقررون استكمال حرب

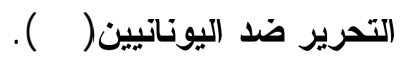

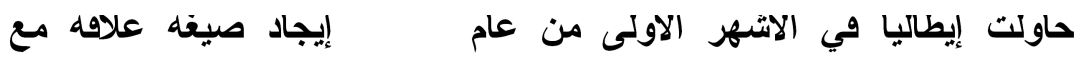
حكومهه السلطان في اسطنبول لضمان الحقاظ عن مصالحها صدر الإمكان وهو ما نستطيع

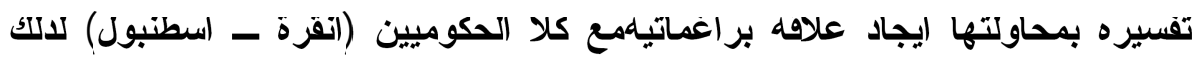
عقد وزير الخارجيه الإيطالي كونت سفورزا مع وزير الخارجيه العتماني بكر سامي بك.

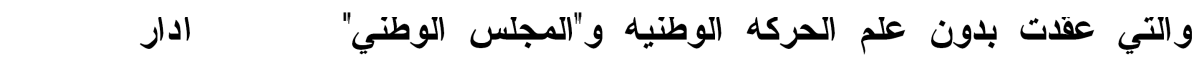
وخلاهها تعهدت إيطاليا بمساعدة الاثراك على استعادة ازمير وتراهيا، على ان يكون النه

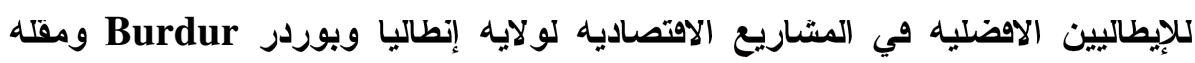
Mugla كما منحت الحق لرجال الاعمال بتمويل استتمار مناجم الفحم وي ارجلي Eregle إلى ولى شركه تركيه إيطاليه. إلا ان الوطنيين روضوها ولم يواهق عليها مصطفى حال الدي فال عنها"انها منحت الكتير من الامتياز ات المعنويه للإيطاليين"(Av).

السياسه الايطاليه وتركيا حتى نهايه معاهدة سيفر: مع بدايه عام .ب19 بات تتطور الاوضاع على الساحتين الدوليه عامه و التركيه خاصه،هق فشلت ووات الحلقاء في القضاء على الحكومه البلشفيه في روسيا،وتزامن هلا الامر مع بلايه انتصارات الحركه الوطنيه التركيه، كدلك بدا الحلفاء 


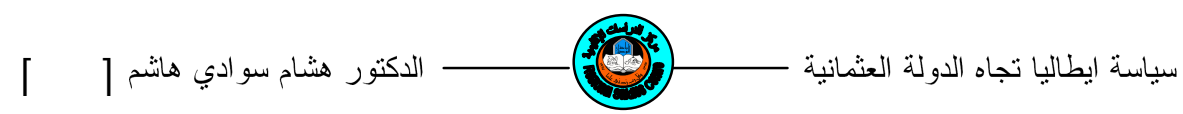

بالسعي إلى عقد معاهدة الصلح مع تركيا باسرع ما يمكن. واتخاد القرار النهائي بشان

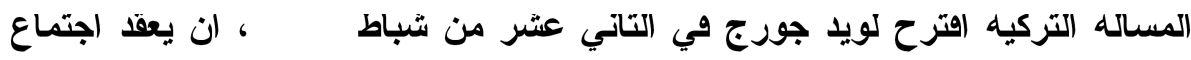
عاجل للبت في الموضوع، ووي الحال واقق مندوبي إيطاليا ورنسا على هل ها الاقتراح.

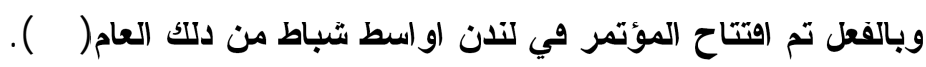

لا تتوفر معلومات حول ما جرى داخل اروفه هدا المؤتمر تحديدا باستتناء

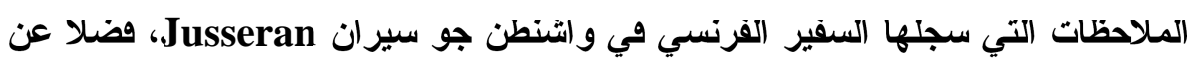

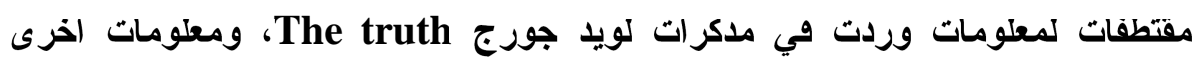
وردت في خطب مصطفى كمال ومع دلك هان هله المعلومات وبخاصه ملاحظات السقير القرنسي تنطوي على ملاحظه وامور مهمه. وفي ضوء تلك المعلومات يمكن التاكيا

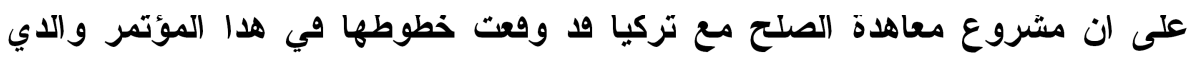

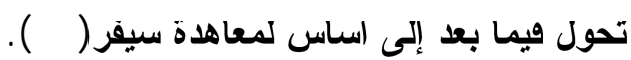
لكن ما يسجل على هلا المؤتمر هو عدم مشاركه الرئيس الامريكي مما جعل مساله تطبيق ما اتقق عليه بين الدول الاوربيه التلاث غير مكتمل لعدم انضمام حليقهم

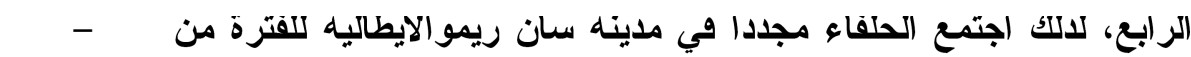
تيسان ·مو1، وحضر الاجتماع رؤساء وزراء كل من إيطاليا وهرنسا وبريطانيا

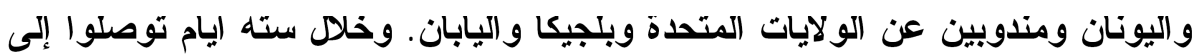
شروط معاهدة السلام مع تركيا. وخلال جلسات المؤتمر تعها المندوب الإيطالي بحمايه

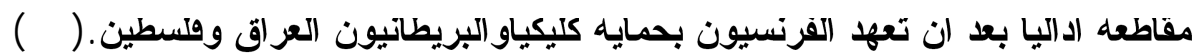

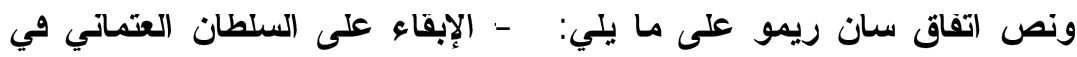
اسطنبول. r - حق الحلقاء وي احتلال الجزء الاوربي من تركيا ومنطقه المضايق. r -

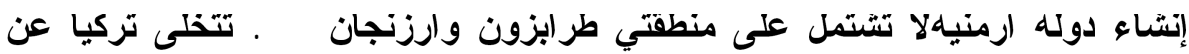
العراق ولفطين والجزيرة العربيه وجزر ايجه.(1)

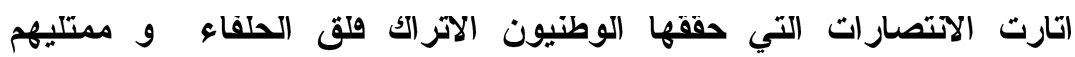
المجتمعين من باريس، لاسيما، وتز امن هلا الامر بتوسع روعه الاحتلال اليوناني لازمير

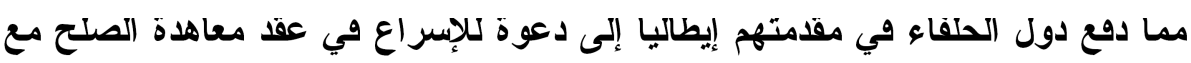


تركيا. ورغم ان الاترالك صدموا بشروط المعاهدة القاسيه مما اضطرهم إلى شجبها ورض التوفيع عليها، الامر الاي جعل الحلفاء يمارسون ضغطا على الآراك بتهايدهم بالطرد من الجزء الاوربي في حاله علم توفيعهم على المعاهدة. وولمت الحكومه التركيه التماسا لاول الحلقاء لتعديل بعض بنودها، غير اتها لم تلق ادانا صاغيه واجبروا اي الاتراك على تويع المعاهلة وي العاثر من اب . موا في مدينه سيقر (القرنسيه (بواج).

نصت المعاهدة التي عروت بمعاهدة سيفر على إنشاء الدوله التركيه في اسطنبول وتخلي السلطان العتماني عن العراق وسوريا وفلسطين التي ستوضع تحت الوصايه البريطانيه والقرنسيه وتخلت ايطاليا بموجب المعاهدةعن جميع مطالبها في جزربحر ايجه. (ما مساله المضايق وقل شكلت لجنه للإثراف عليها سميت بـ"'لجنة المضايق" تكونت من مندوبين اتتين من كل من إيطاليا وورنسا وبريطانيا والولايات المتحدة واليابان واليونان ورومانيا، وض ضمنت كل دوله من الدول الكبرى صوتين

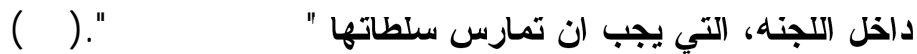

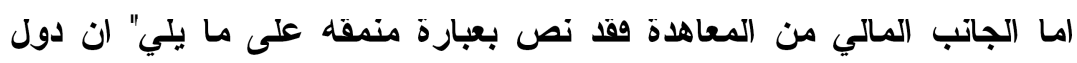
الحلقاء ورغبه منها في اتخاد إجراء لمساعدة تركيا فررت تتكيل لجنه من مندوبي إيطاليا وهرنسا وبريطانيا للإشراف على السيادة الماليه والاهتصاديه والإداريه للبلأ. وتقرر ان يصبح المجلس القديم لإدارة الدين العتماتي مؤلف وقط من ممتلين من إيطاليا

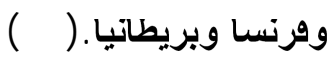

بالإضاهه إلى معاهدة سيفر تم التوصل إلى اتفاق تلاتي بين كل من إيطاليا

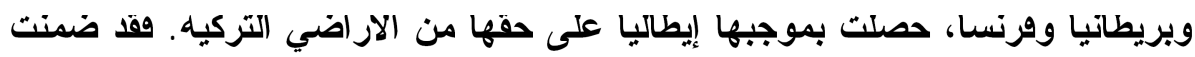

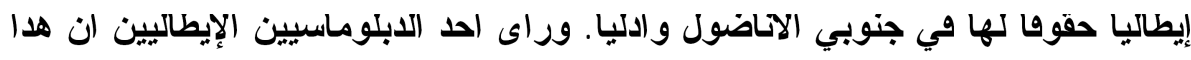
الاتفاق هلف إلى "مساعدة تركيا في تنميه مصادرها الاوليه، وتجنب المناهسه الدوليه

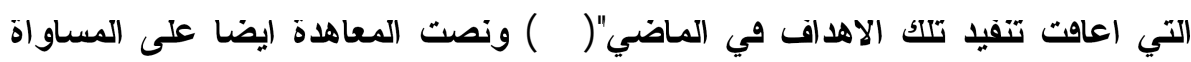
بين الدول التلاث في جميع الهيئات الدوليه المساهميه في إعادة تنظيم تركيا. وكدلك الكي

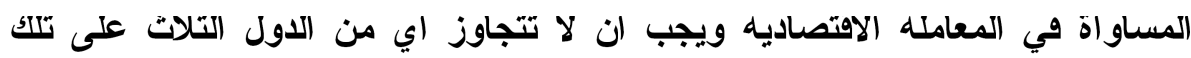
الحقوق في مناطق نقود الدولتين الاخيرتين. وحصل الإيطاليين ايضا على حق استتمار

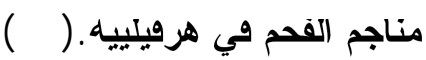




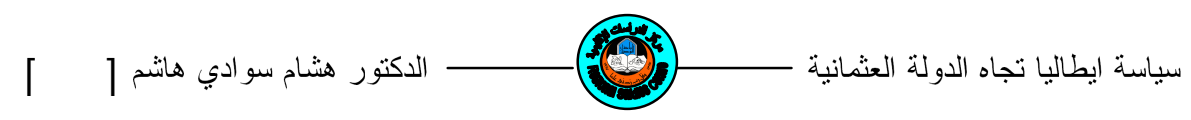

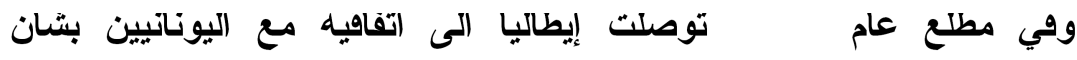
الاناضول. وكاتت إيطاليا بموجب معاهدة سيقر و حصلت على جزر الدودوكاتيز في بحر ايجه. لكن بموجب ها الاتفاق تتازل الإيطاليون لليونان عن جزر بحر ايجه. ونصت الاتفافيه ان تبقى جزيرة رودس تحت سيطرة إيطاليا غير اتها - اي إيطاليا -

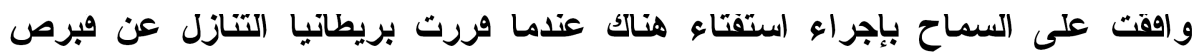

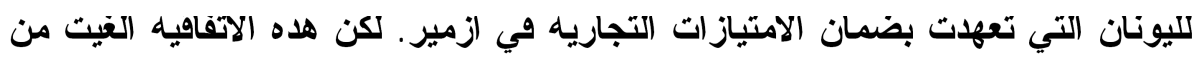
جاتب الإيطاليين في II IMr تموز عندما تولى الكونت سفورزا منصب وزارة (9v)(الخارجيه الإيطاليه. (19)

الخاتمها

صاغت المعاهدات السريه التي عقدها الحلقاءالن الحرب العالميه الاولى سياسه ايطاليا تجاه تركيا في المرحله التي اعقبتهاوفي مؤتمر السلام كان الايطاليين متمسكين

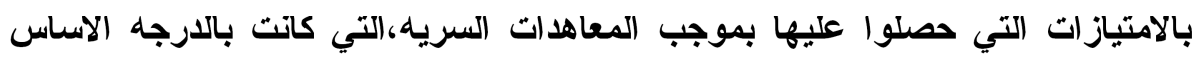

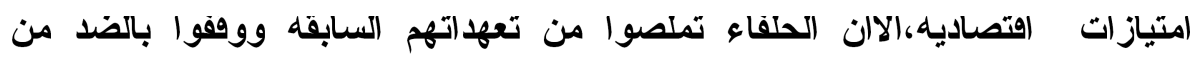

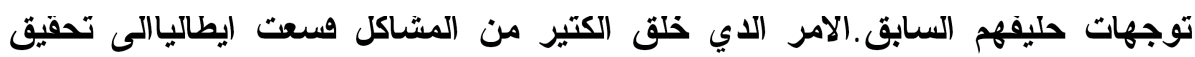
مطاليبها عن طريق الاحتلال العسكري وهدا ماحصل في مساله ازمير عندمانزلت القوات العسكريه الايطاليه ويها نحت دريعه ان هله المنطقه كاتت ممنوحه لهم بموجب معاهدة لندن السريه،لكن المووف المعارض للحلقاء اجبر الايطالين على سحب وواتهم ويما بعد. ومع بروزالحركه الوطنيه التركيه سعت ايطاليا الى ايجاد علاهه خاصه مع الوطنيون كماوله منهم للحصول على مكاسبهم،لاسيما واتهم كانوا يعتبرون حكومده

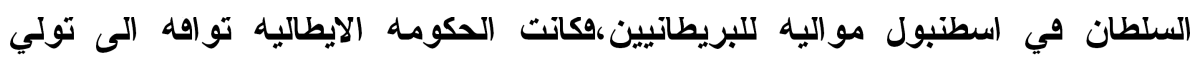

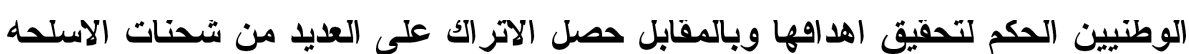
من الايطاليين والتي مكتته من استمرار حربهم ضد اليوناتين. 


\title{
Italian Policy Towards Othman State 1919 - 1921
}

\author{
Dr. Hisham Swadi Hashim \\ lectures, Regional Studies Center, Mosul University, Mosul, Iraq.
}

\begin{abstract}
The secret treaties were hold by the alliances at the time of the First World War, formed the Italian policy towards the Othman state in the stage that followed it. At the peace conference, the Italians were holding on the distinctions which they have got according to the secret treaties, which were firstly economic distinctions, yet the alliances eluded of their previous treaties and stand against the directions of their last alliance. The matter which creates a lot of problems, which made Italy seeks for achieving its demands by means of military occupation, and this is what happened in the problem of Azmeer when the Italian military forces which got down in it under the excuse of being the area is granted to them according to London secret treaty. But the opponent situation for the alliances obliged the Italians to withdraw their forces after then.

At the same time when the Turkish National Movement, Italy tried to find a special relationship with the patriots as an attempt to get their goals, especially, that they consider the Sultan Government in Istanbul is supporting British, so the Italian government longs to support those patriots for achieving its aims and in return the Turkish would got a lot of loads of weapons from Italians which enable them of continuing their fighting against the Greek.
\end{abstract}




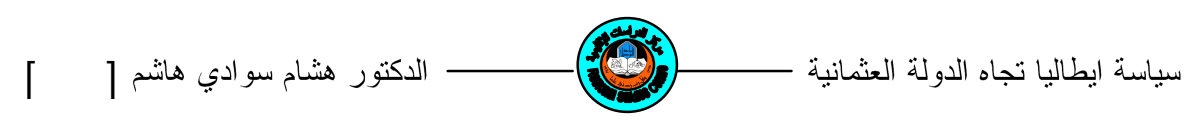

الكهو (مش

(1) ابراهيم خليل احمد وخليل علي مراد، ايران وتركيا. دراسة في التاريخ الحديث

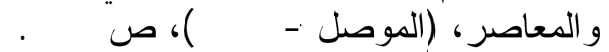

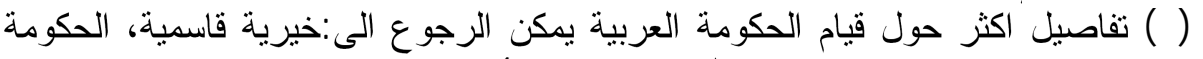

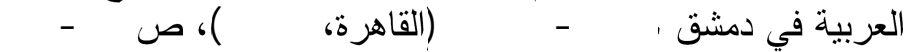

(3) (Lewis, The Emergence of Modren Turkey, (London - 1961) p.234

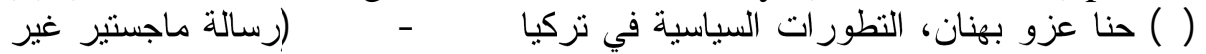

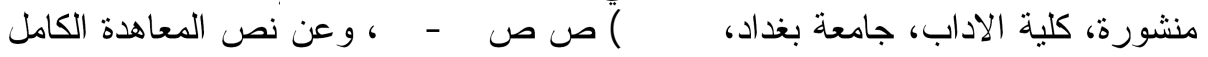

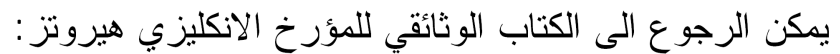
J. C. Huruitz, Diplomacy in the Near and Middle East, Vol, 1l, (New york, 1959) pp129-130

(0) خلال سنوات الحرب العالمية عقد الحلفاء فيما بينهم عدة اتفاقيات سرية لتقسم مناطق

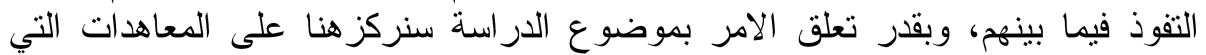

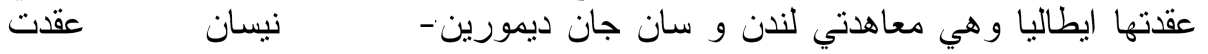

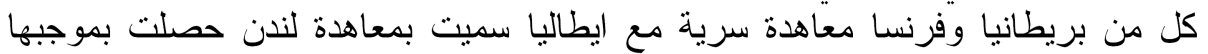

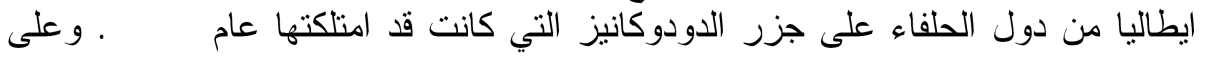

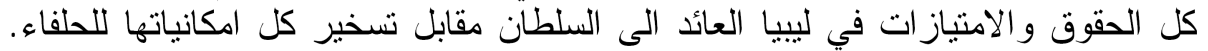

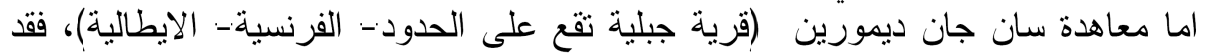

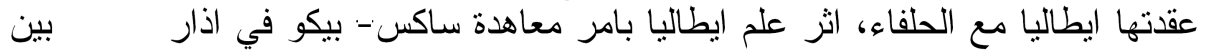

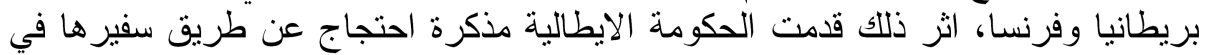

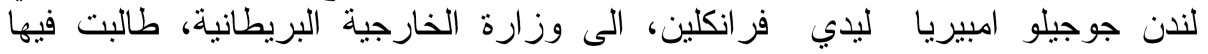

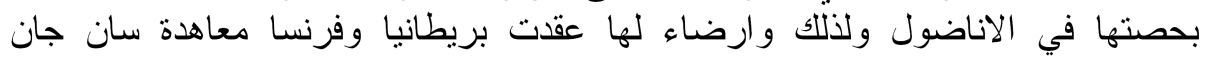

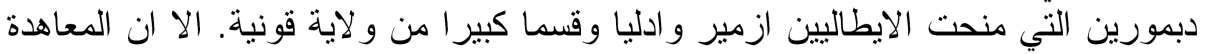

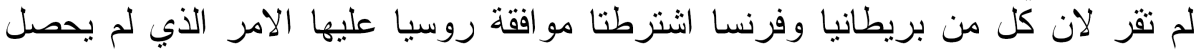
بسبب قيام ثورة اكتوبر في روسيا عام 191

H. W. Temperley, Ahistory of the peace conference of pries vol,6 (oxford, 1969) p.p. 12,20,27.

$$
\text { اهدات انظر: }
$$

J. C. Harewitz, The Middle East, ADocumontary record, V01,2 (New York. 1972) pp 90-96

(6) Lewis, op ,cit. pp, 251-253.

( ) ( ) بهنان، المصدر السابق، ص 
Fr. 1919, vol2 (the secratary of staets to the Minister in suitzerland (store) ) novembr 30. 1918, p.810. Ibid. (The Coting to the secretary of staets to the secretary of Navy (Daniclas)) Decmber24. 1919p-816

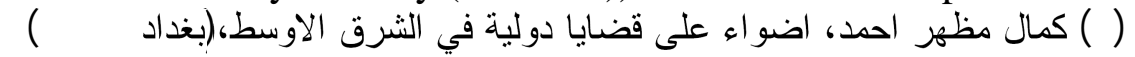

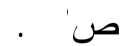

(9) ودورو ويلسون الرئيس الثامن و العشرين للولايات المتحدة الامريكية، ولد في ستونتن

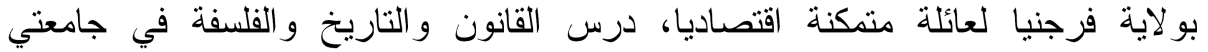

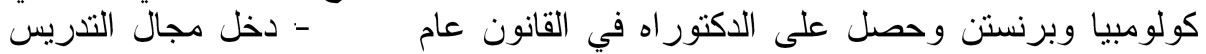

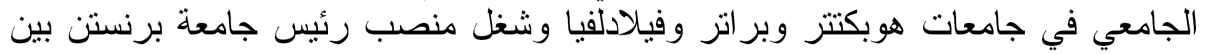

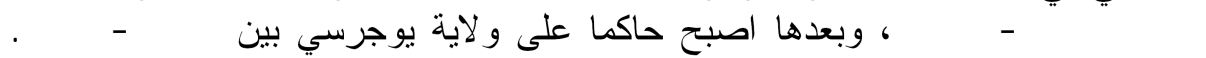

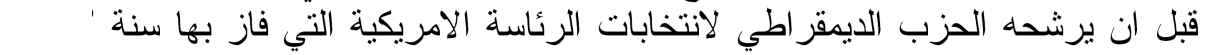

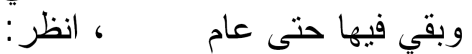

Encyclopaedia Americana, vol 29, pp 6-12

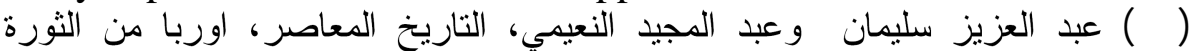

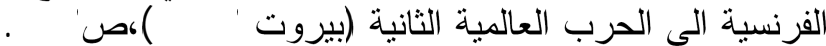

(11) Nicolson Harold, peace making 1919, (washingtan. 1923, p 11,

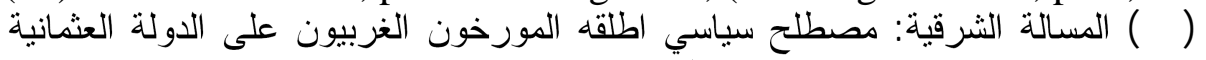

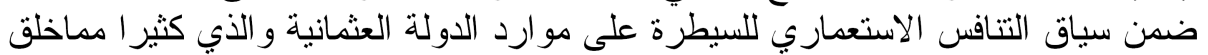

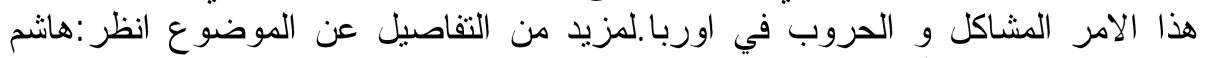

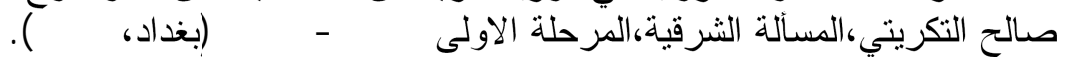

(13) Harry N. Howard, The partition of turkey.A Diplomatic history 1913, 1923, (New York. 1966), p.217

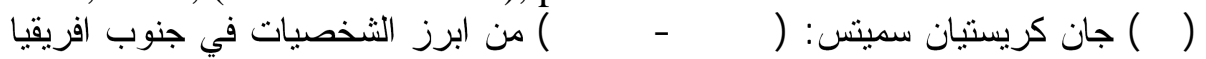

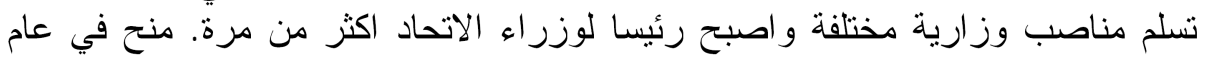

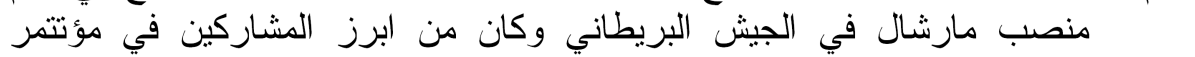

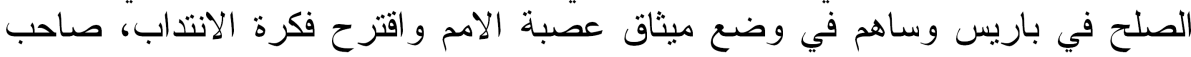
عدد من المؤلفات يدافع معضدها عن النظريات العنصرية.

Encyclopedia Internationa, vol, 16, pp 554-557.

(15) F. B. walter, A History of the legue of Nation,(London, 1967), P 47. 48.

Haward op.cit. P. 221(16).

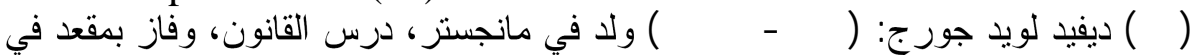

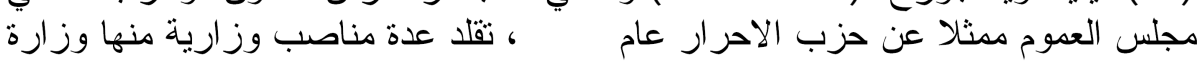

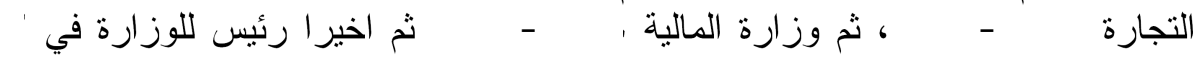

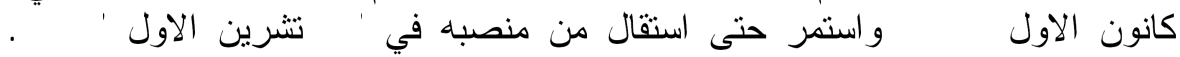
Encyclopedia Britanica, vol, 6, p2811.

(18) Lloyd Goerge, the truth about peace treaties vol '11, (London1938), P 437.

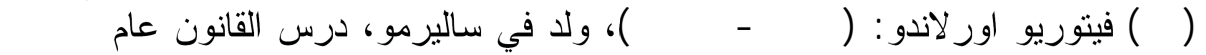

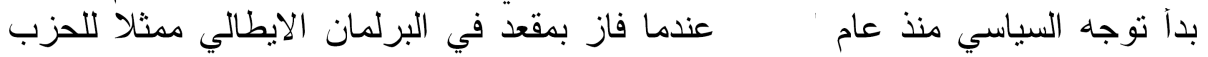




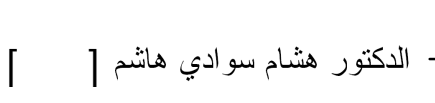
سياسة ايطاليا تجاه الدولة العثمانية

الليبر الي وتدرج في المناصب حتى وصل الى رئاسة الوزر اءو وتر اس الوفد الإيطالي في

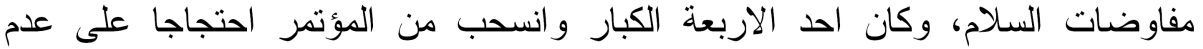

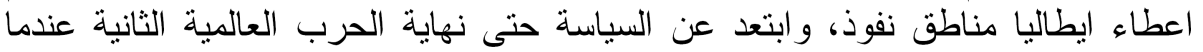

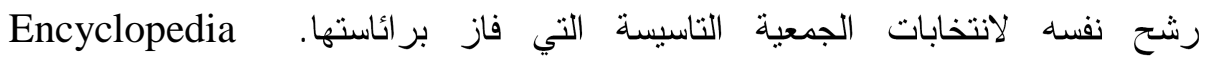

(20) Howard. Op. cit. p 223

(21) Goerge, op. cit. p 441.

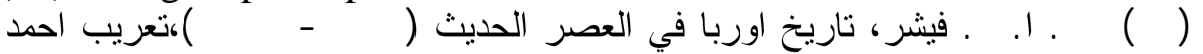

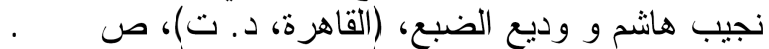

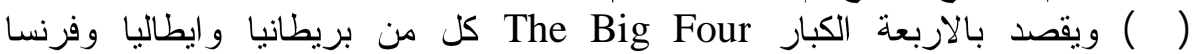

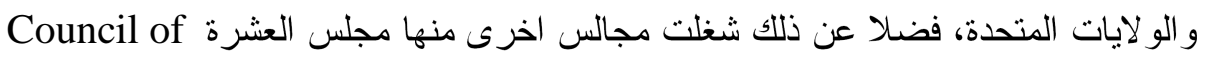

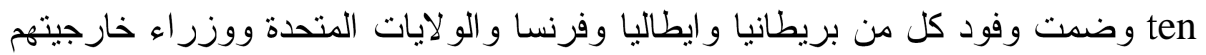

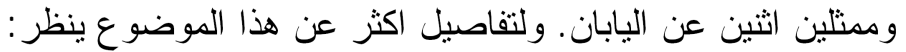

Temperley. Op. cit. vol,1, p,p 167, 181

(24) Gorge, op. cit. pp 149-150

(25) Ibid. p 151

(الاولى الثورة البلثفية:كانت روسيا القيصرية اكبر دولة اوربية قبيل الحرب العالمية

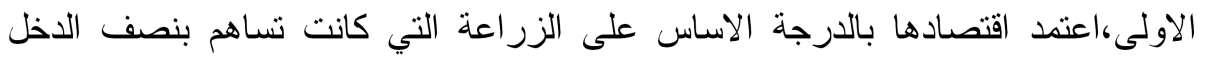

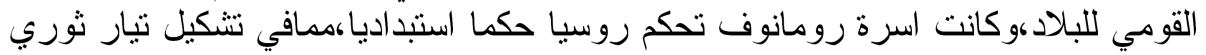

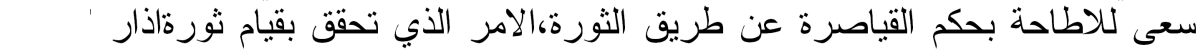

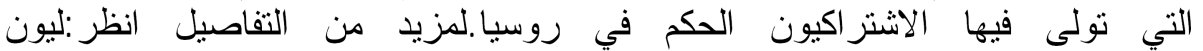

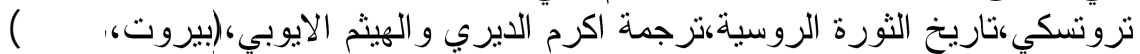

(27) Haward. O. p. cit. p224

(28) FR, 1919, vol, 2, The paris peace conferenice, Wilson to the Secretary of staets 30 Jan Preoident 1919. p.272

(29) Ibid. 276.

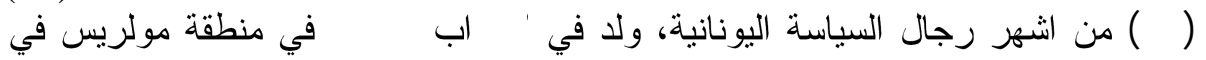

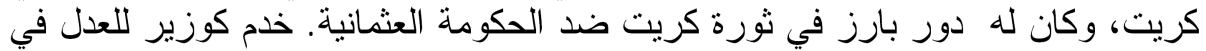

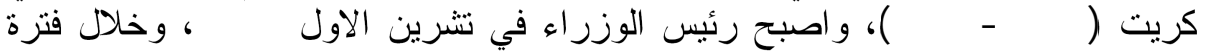

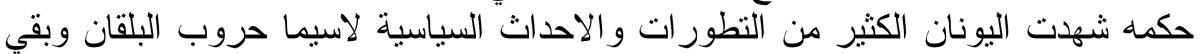

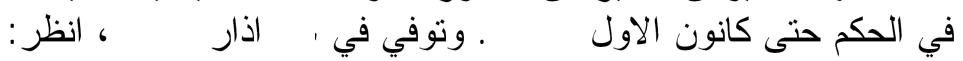

Ensyclopaedia Britannica, Vol, 10. p 389.

(31)Stanford Shaw and Ezel Kural, History of the Ottoman Empire and Modern Turkey, Vol. 2 (London. 1977) p. 330.

(32)M. Sachar, The Emergency of the middle East (1914-1924), (London, 1970), p. 314. 
(34) Temprley op cit. Vol, 6, p. 19

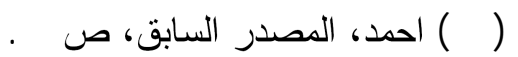

Haward. Op. cit. p. 223 (35)

(36) Ibid p. 223.

Ibid p. 224.(37)

(38) Temprley op cit. Vol, 6, p. 21

Laurence Evans, United State policy and the partition of(39) Turkey, (1914-1924) (Baltimore, 1965), p. 173, Haward. Op. cit. pp. 332-333.

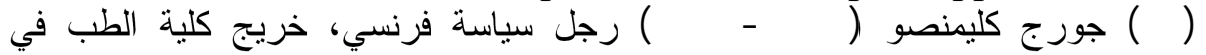

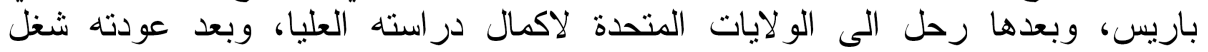

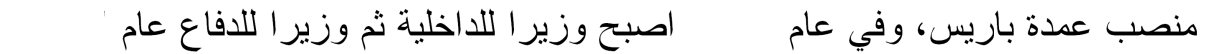

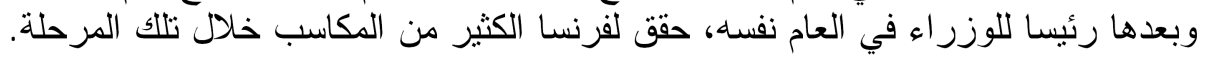

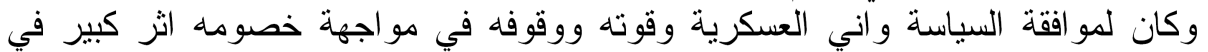

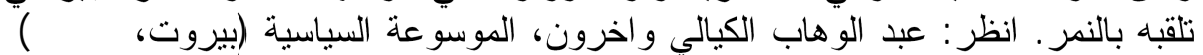

(41) Gorge op. cit, Vol, 11, p. 4998.

(42) Evans, op. cit. p. 173.

(43) Ibid. op. cit. p. 174.

(44) Gorge op. cit, Vol, 11, p. 4998

(45) Ibid. p. 4999.(45)

(46) Evans, op. cit. p. 177

(47) Haward. Op. cit. p. 335.

(48) Ibid. p. 335.

(49) Evans, op. cit. p. 177

(50) Haward. Op. cit. p. 323

(51) Gorge op. cit, Vol, 11, p. 4999

(52) Evans, op. cit. p. 179

(53) Haward. Op. cit. p. 332

(54) Ibid

(55) Haward. Op. cit. p. 235

(56) Sachar. Op. cit. p. 315.

(57) Temperley. Op. cit. p 472

(58) Gorge op. cit, Vol, 11, p. 5227

(59) Evans, op. cit. p. 179

(60) Haward. Op. cit. p. 240

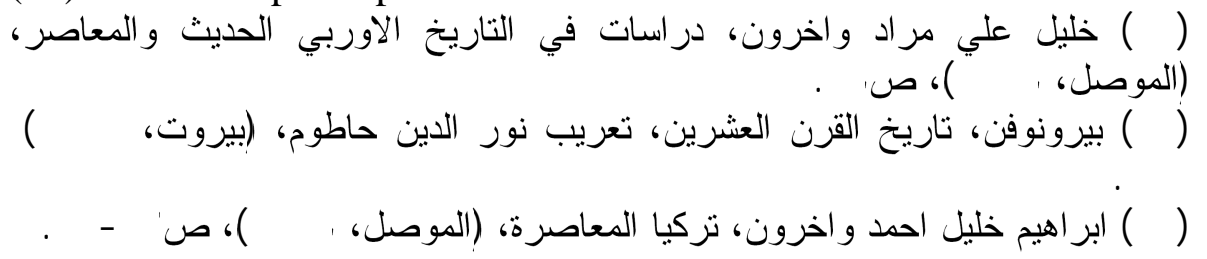




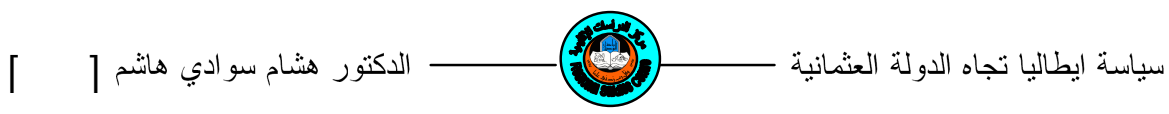

(64) Berber Angin, Kutalustan sonrea Izmirde isgal donemine tepkiler, (Ankara. 1987) S 54.

(65)Ag. G. E. S. 55

(77) مصطفى كمال: ولد في سالونيك سنة 111 | ودرس في مدارسها، ثم انتقل للار اسة

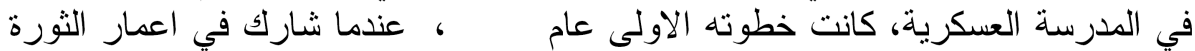

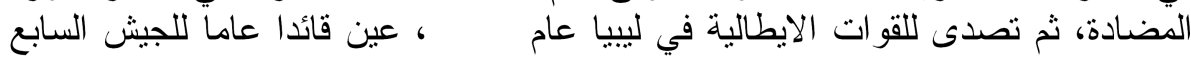

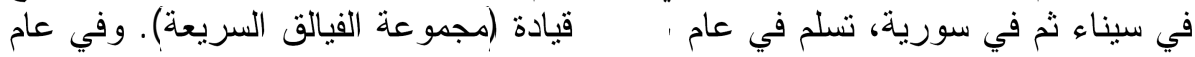

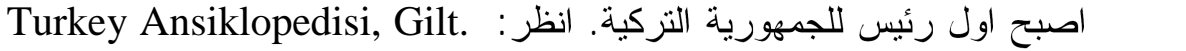
1, ss. 840-901.

(7V)

Norman Low, Nastering Modern world History. (Hong-Kong, 1982) p. 118.

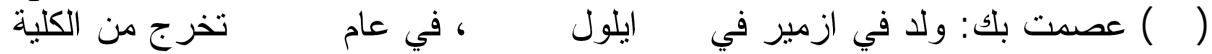

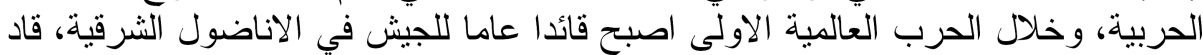

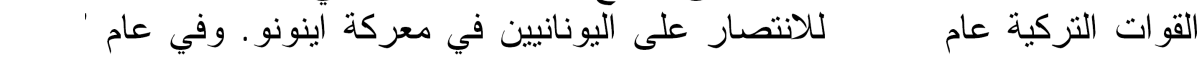

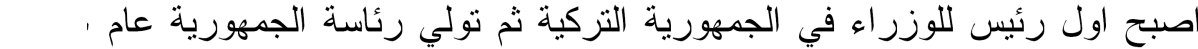

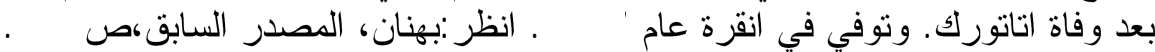

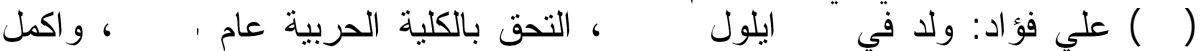

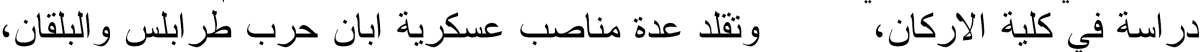

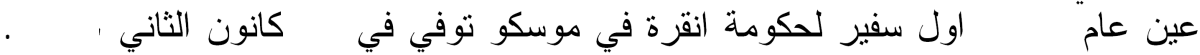

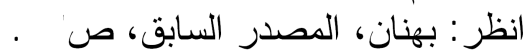

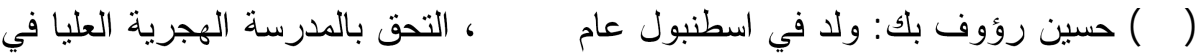

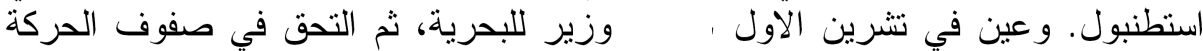

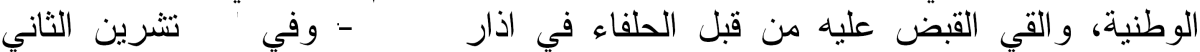

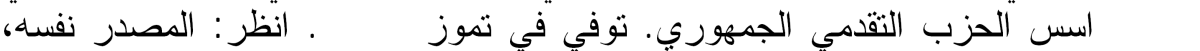
(

(71) Turkish Ministry of press, Proadcasting and Tourism, Gazi Mustafa Kemal Ataturk (Ankara- 1961) p. 82.

(72) Ibid. p. 83.

. بهن (V)

(74) Kemal Kokturk, Ataturk Hayati, Deverimlertre Anilair (Istanbal, 1981), S. 23.

(75) A. E. G. S. 32. 
(76) Roderic H. Davision, a Turkish Diplomacy from Modros to loauzan" in the, gorden A. Caraig, The Diplomats 1919-1939, (London, 1953, p. 173.

(77) Ibid. p. 178

(78) Ibid. p. 179

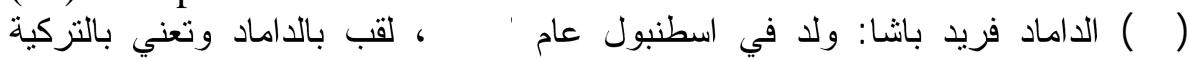

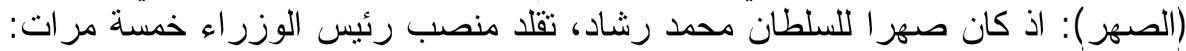

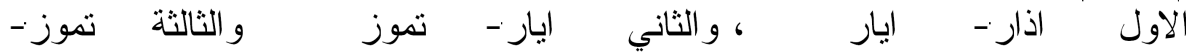

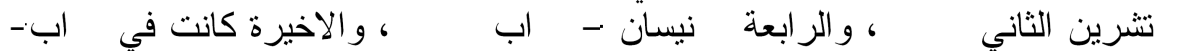

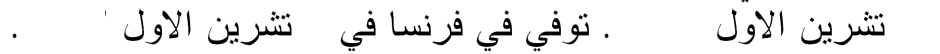

Turk Anaklopedisi, Gilt. 16. ss 441-442.

(80) Haward, op. cit. p. 231.

(81) Salahi Ramsdam Sonyel, Turkish Diplomacy, 1918-1923, (AnKara. 1985). P. 71

(82) Davison, op. cit. p. 176.

(83) Haward. Op. cit. p. 233.

(84) Ibid, p. 234.

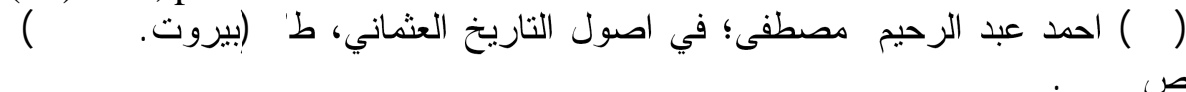

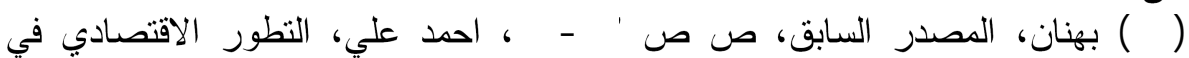

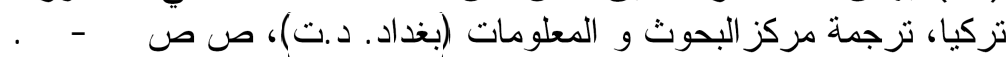

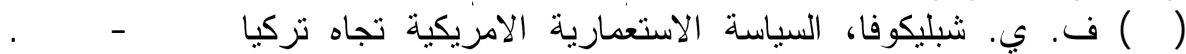

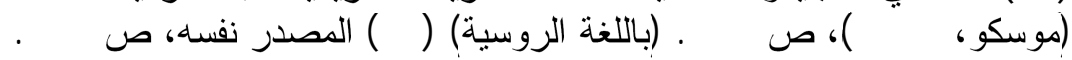

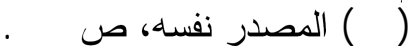

(89) Arnold Toynbee, Survery of International Affairs 1920_1923, London, 1927, p. 9.

(90) Ibid.

Haward op cit. P. 240

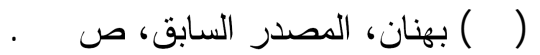

(93) Haward op cit. p. 240

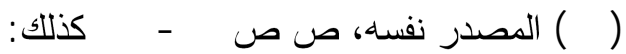

(94) Ibid. p. 241

(95) Ibid.

(196) Ibid.

(97) Ibid. 